\title{
Os efeitos da elevação do nível do mar e do balanço sedimentar em um hotspot erosivo no litoral do Rio Grande do Sul, Brasil
}

\author{
Matheus de Assis BOSE1, Salette Amaral de FIGUEIREDO 1,2, Lauro Júlio CALLIARI², \\ Jorge ARIGONY-NETO ${ }^{1,2}$, Elaine Siqueira GOULART'2, João Augusto de Carvalho \\ FERREIRA ${ }^{3}$ \& Miguel da Guia ALBUQUERQUE ${ }^{3}$
}

\begin{abstract}
1 Programa de Pós-Graduação em Oceanografia Física, Química e Geológica, Universidade Federal do Rio Grande. Av. Itália, km 8, CEP 96.201-900, Carreiros, Rio Grande, RS, Brasil (matheusoceano@gmail.com, saletteoc@gmail.com).

2 Instituto de Oceanografia, Universidade Federal do Rio Grande. Av. Itália, km 8, CEP 96201-900, Carreiros, Rio Grande, RS, Brasil (Icalliari@log.furg.br, jorgearigony@furg.br, elainegoulart@gmail.com).

3 Instituto Federal de Educação, Ciência e Tecnologia do Rio Grande do Sul, Campus Rio Grande. Rua Eng. Alfredo Huck, 475, CEP 96.201-460, Centro, Rio Grande, Brasil (joao.ferreira@riogrande.ifrs.edu.br, miguel.albuquerque@riogrande.ifrs.edu.br).
\end{abstract}

\begin{abstract}
Resumo. Este artigo mostra os impactos da elevação do nível do mar (ENM) e do balanço sedimentar (BS) no recuo da linha de costa (LC) para 2041 e 2100, no setor do Farol da Conceição, Rio Grande do Sul, Brasil. Para entender estes comportamentos na região foi usado um modelo de larga escala, Randon Shoreface Translation Model (RanSTM), capaz de simular o efeito ENM, do BS e da geomorfologia na variação da LC. Foram realizadas quatro simulações distintas, visando: i) estimar o BS de 1996-2018, utilizando a taxa de ENM regional; ii) projetar as futuras LC para 2041 e 2100, baseados nas estimativas da ENM para o século XXI; iii) quantificar a influência isolada da ENM e do BS nas taxas de recuo da LC; iv) analisar a influência da geomorfologia da antepraia adjacente no recuo. Os resultados encontrados para as simulações mostram um déficit de sedimento de $-1000 \mathrm{~m}^{3} / \mathrm{m}$ para o período de 1996-2018, e a taxa de recuo da LC foi de $-2,95 \mathrm{~m} /$ ano. As projeções mostram que as taxas médias de erosão vão aumentar para 2041 e 2100 (-3,85 e -4,23 m/ano, respectivamente). Nas últimas décadas e para 2041 o recuo da LC foi dominado pelo BS negativo; no entanto para 2100 a principal componente do recuo é a ENM. Quando analisado a influência da geomorfologia, o setor com a menor declividade apresentou as maiores taxas de recuo da LC.
\end{abstract}

Palavras-chave. Mudança climática, evolução costeira, modelagem e projeção futura da linha de costa.

\begin{abstract}
THE EFFECTS OF SEA LEVEL RISE AND SEDIMENT BUDGET OVER AN EROSIONAL HOTSPOT AT THE COASTLINE OF RIO GRANDE DO SUL, BRAZIL. This article shows the impact of sea level rise (SLR) and sediment budget (SB) over the incoming shoreline retreat 2041 and 2100 at the Conceição Lighthouse sector, Rio Grande do Sul, Brazil. The simulation of the effects of SLR and SB over the shoreline was made using a large-scale model, the Random Shoreface Translation Model (RanSTM), capable to simulate the effect of SLR, SB and geomorphology over the shoreline. Four distinct simulations were performed: i) estimation of the SB for the period between 1996-2018, considering regional sea level rise; ii) shoreline projections for 2041 and 2100 , based on the estimation of the SLR for the 21 st century; iii) calculation of the influence of the SLR and SB over the variation of the shoreline; iv) analysis of the geomorphology influence over erosion rates. The results for the simulations show a sediment deficit of $-1000 \mathrm{~m}^{3} / \mathrm{m}$ for the period between 1996 and 2018, and the shoreline variation rate was -2,95 m/year. Projections show that average erosion rates will increase for the next years; by 2041 it will be $-3,85 \mathrm{~m} / \mathrm{year}$ and by 2100 will be $-4,23 \mathrm{~m}$ / year. In the last decades, and for 2041 the shoreline is controlled by the negative SB. However, the projected shorelines for 2100 show that the SLR is controlling. When analyzing the geomorphology influence over the shoreline retreat, the low gradient sector showed the highest rates of erosion.
\end{abstract}

Keywords. Climate change, coastal evolution, modeling and future projection of the shoreline. 


\section{Introdução}

Ao longo das últimas décadas, a comunidade científica vem estudando a variação da linha de costa (LC) em relação à variação do nível do mar (Bruun, 1962; Cowell et al., 2003a, 2003b; Nicholls et al., 2011; Le Cozannet et al., 2014). No último século, o nível do mar subiu, decorrente do derretimento dos gelos e pela expansão térmica dos oceanos, causado pela mudança climática antropogênica (Milne et al., 2009; Church et al., 2011). Simulações para as próximas décadas indicam um aumento na taxa de elevação do nível do mar (ENM) (com a possibilidade de o nível chegar a 0,5 a $1 \mathrm{~m}$ acima do atual em 2100), em decorrência destas mudanças (Church et al., 2013; IPCC, 2014). Desta forma, existe uma crescente preocupação sobre o impacto da aceleração da ENM na zona costeira, em relação às taxas de recuo da LC (Le Cozannet et al., 2014).

No entanto, a ENM não é o único fator responsável pelo recuo da LC. Diversos fatores e processos de diferentes escalas espaciais e temporais influenciam a sua variação, como exposto na figura 1 (Bird, 1996; Stive, 2004), diferentes tipos de costas não vão ter a mesma resposta em relação a mesma taxa de variação do nível do mar (Gornitz, 1991; Fletcher, 1992).

Diante dos cenários apresentados para as projeções de ENM em relação às mudanças climáticas no século 21 (IPCC, 2014; Jackson \& Jevrejeva, 2016), faz-se hoje necessário prever o recuo da LC, devido à alta concentração da população na zona costeira (Cooper \& Pilkey, 2004). Estudos de larga escala vêm sendo amplamente aplicados nesta área, pelo fato de trabalharem em uma escala de tempo relevanteàs mudanças climáticas (Cowell et al., 2003a, 2006). A retrogradação da LC é resultado de três fatores: ENM, balanço sedimentar (BS) e geomorfologia (Carter \& Woodroffe, 1994; Figueiredo, 2013). A configuração geomorfológica (característica do substrato ou relevo) deve ser considerada diante do cenário da mudança climática, já que para diferentes morfologias a LC vai apresentar comportamento diferentes (Dillenburg et al., 2000; Slott et al., 2010).

O presente estudo visa analisar o recuo da LC dos últimos 23 anos e projetar o mesmo para 2041 e 2100, em um setor costeiro localizado no litoral médio do Rio Grande do Sul (RS), caracterizado por apresentar erosão permanente (Dillenburg et al., 2000, 2004, 2005; Figueiredo, 2013; Bitencourt et al., 2020). Para isso, foi aplicado o modelo de evolução de larga escala Randon Shorface Translation Model (RanSTM), capaz de modelar a variação da LC em relação aos parâmetros de ENM, do BS e da geomorfologia do substrato. Sendo assim, simulações com configurações geomorfológicas distintas foram realizadas, para analisar o efeito da antepraia local no recuo da LC, e também foi possível quantificar o efeito do BS e da ENM para o recuo da LC.

\section{2 Área de estudo, materiais e métodos}

\section{1 Área de estudo}

\subsubsection{Características geológicas e oceanográfi- cas}

A costa do Rio Grande do Sul (RS) está localizada no sul do Brasil $\left(29^{\circ} \mathrm{S}\right.$ e $\left.34^{\circ} \mathrm{S}\right)$, caracterizada por apresentar um sistema de laguna-barreira dominado por ondas, com uma extensão de 623 km, apresenta conformações côncavas e convexas, garantindo um formato levemente ondulado (Fig. 2B) (Dillenburg et al., 2000). A LC se estende desde a desembocadura do Rio Mampituba, ao norte, até a desembocadura do Arroio Chuí ao sul. A costa é interrompida em duas regiões: na desembocadura da Lagoa dos Patos e da Laguna de Tramandaí, nas cidades de Rio Grande e Tramandaí respectivamente. Intermitentemente temos as aberturas das Lagoas do Peixe e do Estreito, ambas localizadas no litoral médio (Dillenburg \& Barboza, 2014).

O clima do estado do RS é caracterizado como temperado úmido, a chuva é bem distribuída ao longo do ano (Alvares et al., 2013). O regime de maré é classificado como micro maré (Davies, 1980), entretanto, o vento e a pressão atmosférica desempenham o papel principal nas oscilações de curto período do nível do mar ao longo da costa.

O clima de ondas na costa do RS apresenta 


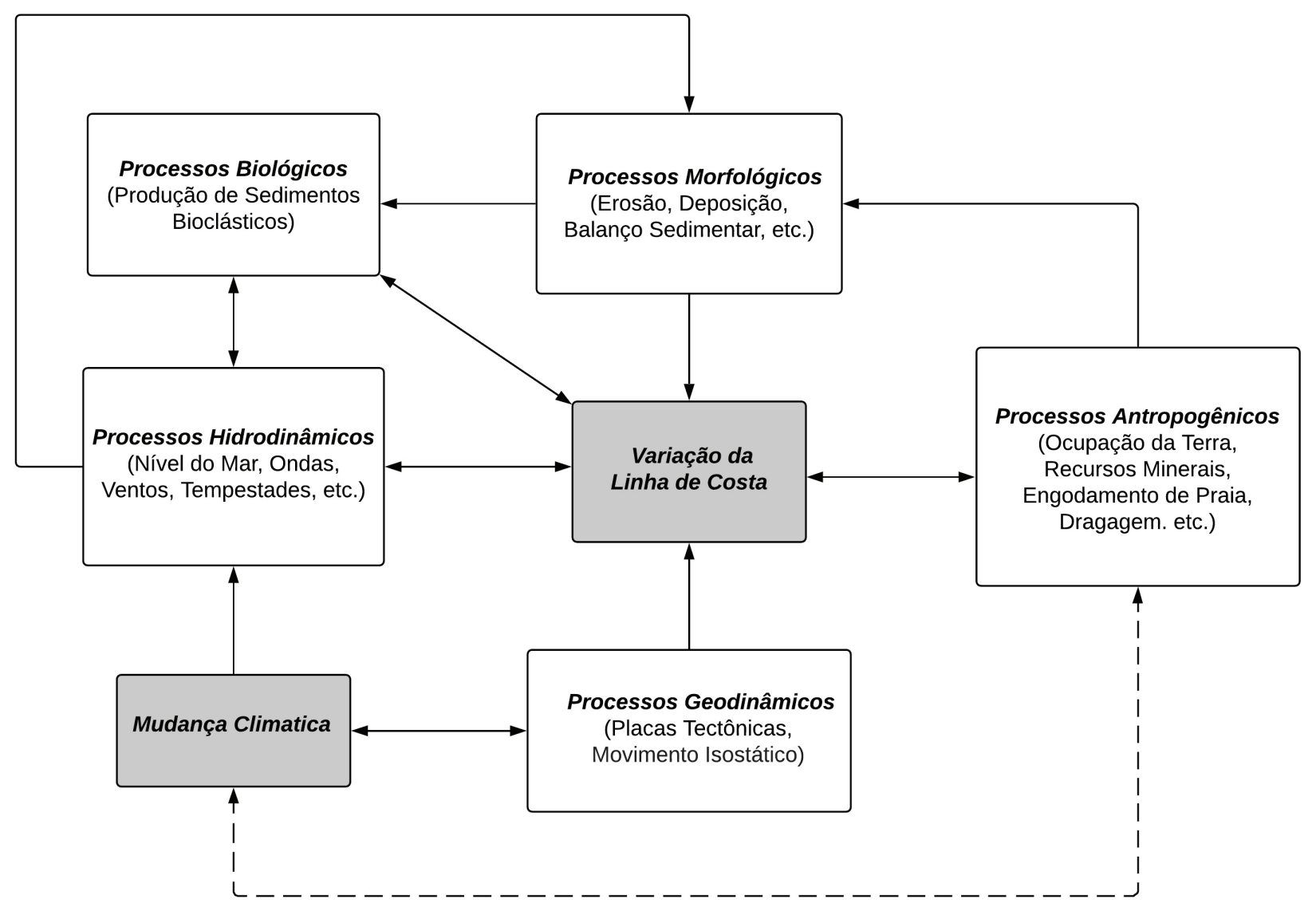

Figura 1. Diferentes categorias e processos que envolvem o recuo da LC. As setas mostram a interação entre os processos. Devido à interação entre os mesmos a variação da linha de costa pode estar relacionada a vários fatores (modificado de Le Cozanne et al., 2014).

Figure 1. Different categories of processes involved in shoreline displacement. Interactions and feedbacks between these factors are indicated by arrows. Because of the multiplicity of factors, processes, interactions and feedbacks, shoreline changes are attributed to several causes (modified from Le Cozanne et al., 2014).

um comportamento sazonal. Durante a primavera e o verão (meses de outubro a fevereiro), as ondas são geradas por ventos locais, dos quadrantes norte e leste e são denominadas vagas, as quais possuem menos energia. Já as ondas de maiores energias são geradas durante o outono e o inverno (meses de abril a julho), provenientes do quadrante sul, na forma de swell e são associadas à passagem de frentes frias (Calliari et al., 1998; Barletta \& Calliari, 2003; Romeu et al., 2015). 0 resultado da corrente de deriva litorânea tem direção para o norte, a qual pode ser evidenciado pelos indicadores geomorfológicos discutidos por Tomazelli \& Villwock (1992) e quantificados por Lima et al. (2001) e Motta et al. (2015). Martinho et al. (2009) afirmam que apesar da frequência das ondas oriundas do quadrante sul ser menor ( $9 \%$ ) do que a frequência do quadrante norte (13\%), estas são responsáveis por 30\% do transporte de sedimento ao longo da costa pela corrente de deriva.
Atualmente, as praias do RS não recebem aporte significativo de sedimentos terrígenos. A maioria dos sedimentos transportados pelos rios ficam retida nos sistemas lagunares e em outros ambientes costeiros (Tomazelli et al., 1998). Desta maneira, o BS da costa é controlado pelo transporte longitudinal e perpendicular de sedimentos (Martinho et al., 2009).

Dillenburg et al. (2000), analisando 25 perfis batimétricos, calcularam a declividade da plataforma continental do RS que varia de $0,027^{\circ}$ a $0,125^{\circ}$ (Fig. 2B, observar a isóbata de $50 \mathrm{~m}$ ). A declividade varia de acordo com a orientação da LC, do setor côncavo para convexo (projeção), a declividade da plataforma interna vai ficando mais íngreme, e quando a LC varia de convexa para côncava (embaiamento) a declividade se torna mais suave.

Estas características morfológicas, orientação da LC e declividade da plataforma continental interna, geram um gradiente de 


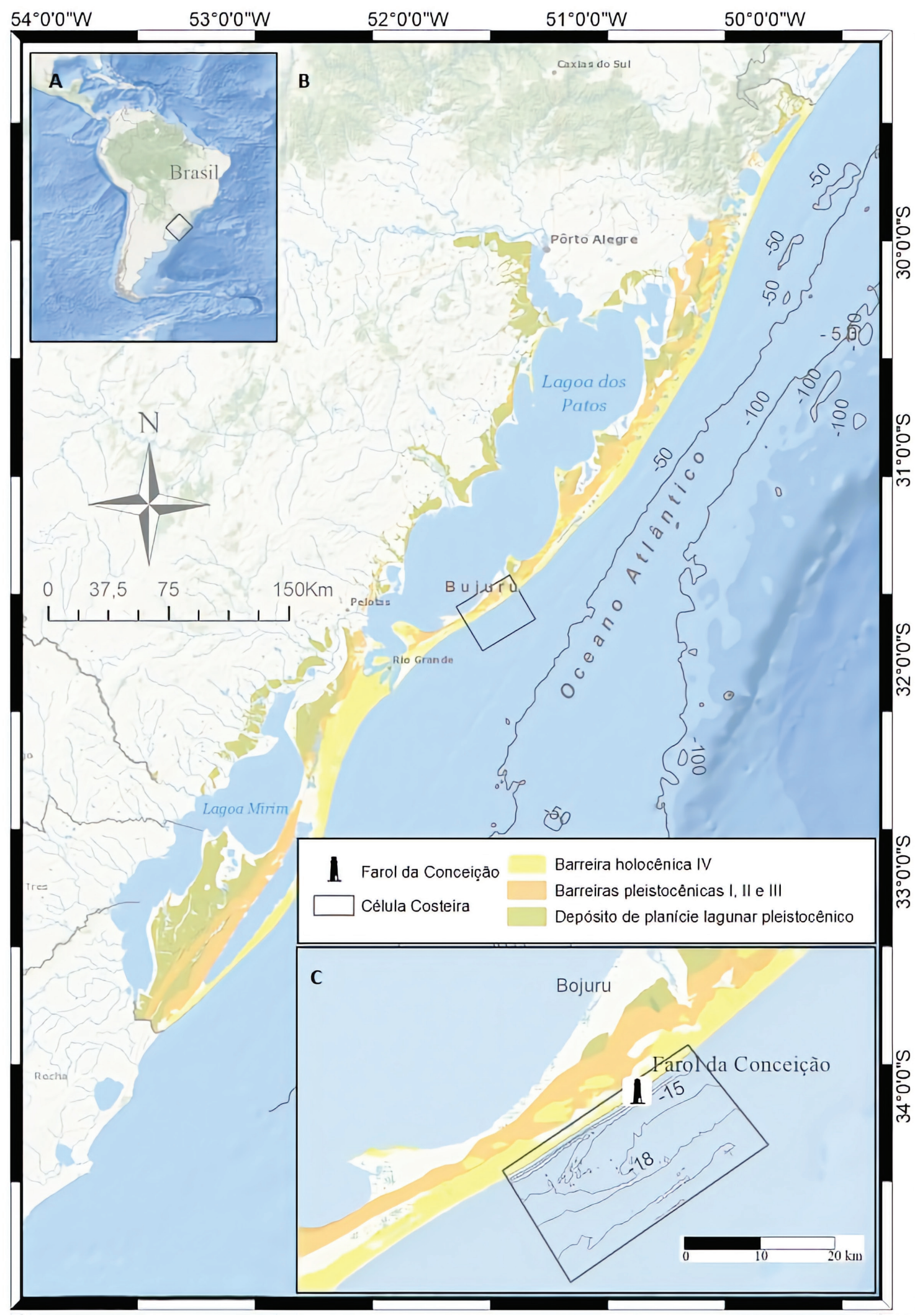

Figura 2. Mapas de localização da área de estudo (fontes: Esri, USGS, NOAA). A) Mapa da América do Sul; B) Geomorfologia Costeira do Rio Grande do Sul (fonte: Serviço Geológico do Brasil); C) Célula Costeira da região com a batimetria detalhada da região do Farol da Conceição (Goulart, 2010).

Figure 2. Maps of the localization of the study area (source: Esri, USGS, NOAA). A) South America map; B) Coastal Geomorphology of Rio Grande do Sul (source: Geological Service of Brazil); C) Costal Cell with the detailed bathymetry of the Conceição Lighthouse region. 
energia de onda ao longo da costa (Dillenburg et al., 2003; Martinho et al., 2009). Nos setores com maiores declividades, concentram-se maiores energias de onda, resultando em erosão costeira. Já nos embaiamentos onde a declividade é menor, a energia de onda é dispersa, levando a deposição de sedimento (Dillenburg et al., 2000). A diferença de energia de onda ocorre de acordo com os processos de: convergência dos raios de onda, o que leva a ter maiores energias próxima das projeções costeiras, e menores energias nos embaiamentos devido à dispersão dos raios. Ao mesmo tempo, existe o processo de dissipação da energia de onda causado pelo atrito com o fundo, nos embaiamentos (menores declividade) o atrito é maior, portanto maior a dissipação, já nas projeções (maior declividade), menor é o atrito das ondas com o fundo, levando a menor dissipação da energia. Em decorrência do gradiente de energia onda ao longo da costa o transporte longitudinal de sedimento resultante será para o NE, a areia sai das projeções costeiras e deposita nos embaiamentos (Lima et al., 2001).

\subsubsection{Evolução costeira}

O modelo evolutivo da costa do RS mais aceito é descrito por Villwock et al. (1986), nas quais são identificados quatro sistemas laguna-barreira formadas durante as sucessivas variações do nível do mar no Quaternário. As barreiras I, II e III datam do Pleistoceno. A barreira IV contém a atual LC e tem uma idade holocênica, com formação iniciada há 7 ka. Cada sistema representa um limite de um evento de máxima transgressão marinha (Villwock \& Tomazelli, 1995; Tomazelli et al., 2000; Rosa et al., 2017).

Há 17,5 ka, o nível do mar estava cerca de 120 - 130 m abaixo do nível atual (Corrêa, 1996). De 17,5 a 6,5 ka, o nível do mar se elevou a uma taxa de 1,2 cm/ano, atingindo aproximadamente 2 m acima do nível atual, há cerca de 5,6 ka (Angulo et al., 2006) e também junto a região de estudo, na Lagoa dos Patos, Barboza \& Tomazelli (2003) apresentam um nível de base para o máximo eustático do Holoceno entre 2 - 3 m acima do nível atual. De 5,6 ka até o presente, o nível do mar apresentou um rebaixamento pequeno de 0,4 mm/ano (Dillenburg et al., 2004; Martinho et al., 2009).

Martinho et al. (2009), baseados em estudos anteriores, concluíram que o gradiente de energia de onda, ao longo da costa, controla o BS dos setores côncavos e convexos, determinando dessa forma os tipos de barreiras encontrados no RS. Nas projeções, onde a erosão costeira leva a um BS negativo, encontramos as barreiras retrogradantes. Nos embaiamentos, onde há deposição sedimentar, desenvolvem-se as barreiras progradantes.

A área de estudo está localizada próximo da cidade de Bojuru, no Farol da Conceição (Fig. 2) e apresenta uma extensão de aproximadamente $26 \mathrm{~km}$. O setor é caracterizado como um hotspot erosivo, que segundo Speranski \& Calliari (2004) é uma zona litorânea que apresenta uma sequência histórica de retração da LC. Trabalhos anteriores (Tomazelli \& Dillenburg, 1998; Tomazelli et al., 1998; Dillenbug et al., 2000, 2004; Barletta \& Calliari, 2003; Buchmann \& Tomazelli, 2003; Machado, 2014; Pereira et al., 2007) apontam que este setor da costa é dominado por eventos erosivos há aproximadamente $5 \mathrm{ka}$. Algumas das evidências deste processo erosivo são os afloramentos de turfas e lama lagunar na praia, a existência de uma escarpa praticamente continua ao longo das dunas frontais e a formação de dunas transgressivas (Fig. 3). Para este setor a barreira é caracterizada como retrogradante (Dillenbug et al., 2000; Barboza et al., 2011).

Na região da antepraia existe a presença do Banco Capela (Fig. 4), localizado a 2 km da costa e se estende até $9 \mathrm{~km}$ aproximadamente, sua profundidade varia entre 9 e 13 m e encontrase a $12 \mathrm{~km}$ a sudoeste do Farol da Conceição. Segundo Goulart (2010) o banco é uma feição morfológica fixada a uma estrutura rígida, possivelmente um parcel de arenito de praia, modelada pela interação com a hidrodinâmica e o sedimento disponível. A presença deste banco na antepraia influencia diretamente a erosão da LC, de duas maneiras antagônicas: primeiramente o banco promove a dispersão da energia de onda e levando a diminuindo da erosão; e por outro lado, o sedimento que é transportado em direção ao mar, além da feição, em situações extremas de tempestade, e que tenderia a ser transportado de volta à costa, o banco acaba atuando como 

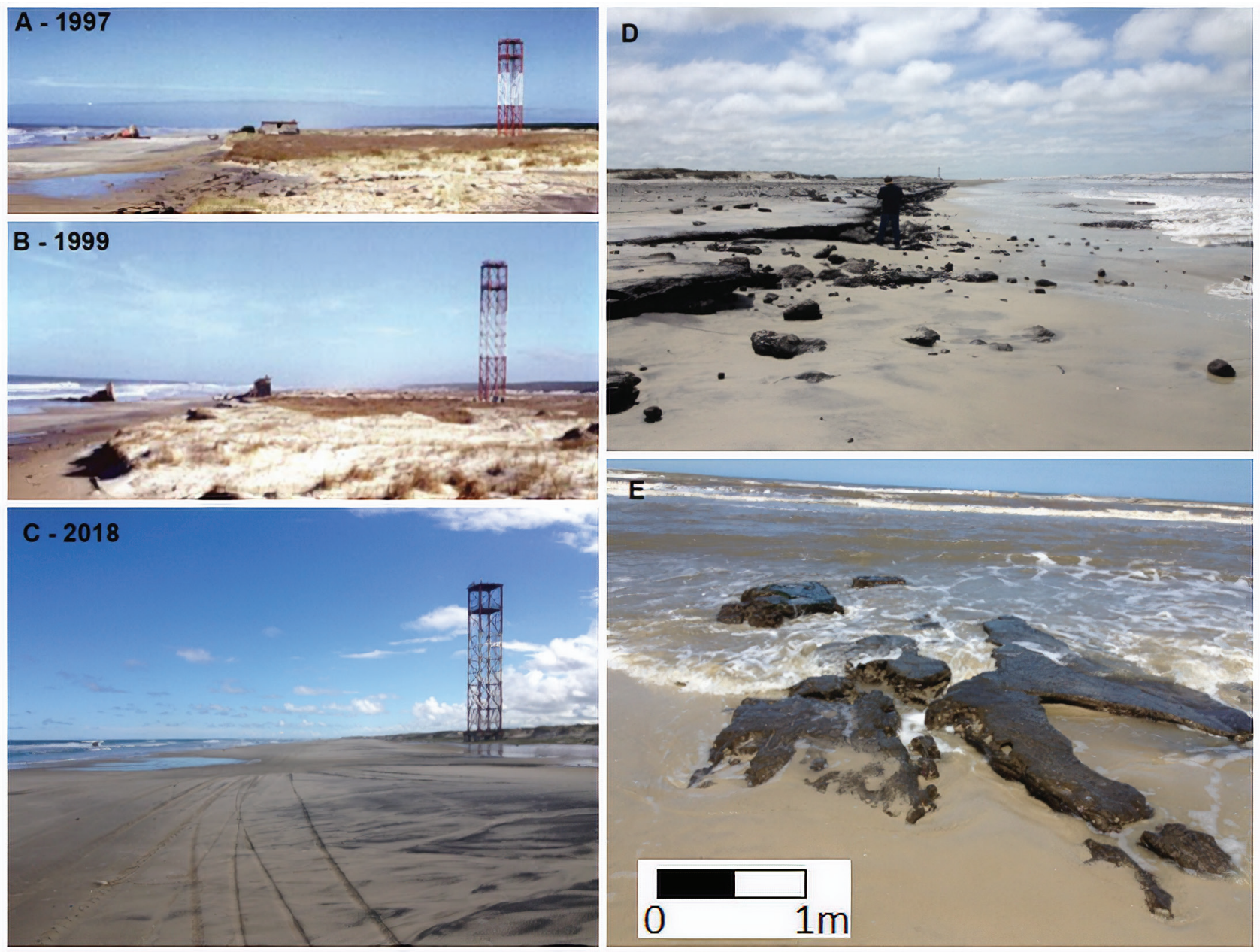

Figura 3. Fotos da região do Farol da Conceição. A) Imagem do Farol de 1997 (fotografia: Elírio Toldo Junior); B) Imagem do Farol de 1999 (fotografia: Elírio Toldo Junior); C) Imagem do Farol de 2018; D) Afloramento de turfas na praia; E) Afloramento de lama lagunar.

Figure 3. Photograph of the Conceição Lighthouse. A) Photograph of Lighthouse in 1997(photography: Elírio Toldo Junior); B) Photograph of Lighthouse in 1998 (photography: Elírio Toldo Junior); C) Photograph of Lighthouse in 2018; D) Peat outcrop on the beach; E) Lagoon mud outcrop on the beach.

uma barreira física que impede que este ciclo se complete, sendo assim, responsável por um défıcit de sedimentos na praia adjacente (Goulart, 2010).

\subsection{Metodologia}

Para a realização da pesquisa, uma série de procedimentos foram necessários. Parte dos dados foram coletados em campo, depois processados e analisados como demostrado na figura 5.

\subsubsection{Levantamento de campo}

Foram realizados quatro trabalhos de campo, nos quais foram coletos perfis de praia e posicionados 25 pontos de controle (PC) no campo de dunas, sendo 18 marcos de concreto pintados de vermelho e sete alvos de lona, que em seguida foram georreferenciados utilizando um GPS RTK (Real Time Kinematic), para obter as coordenadas (latitude $\mathrm{x}$ longitude $\mathrm{x}$ elevação elipsoidal) dos PC. Em seguida foram coletadas as imagens aéreas através do veículo aéreo não tripulado (VANT) (drone, modelo DJIPhantom $\left.4^{\circledR}\right)$, 


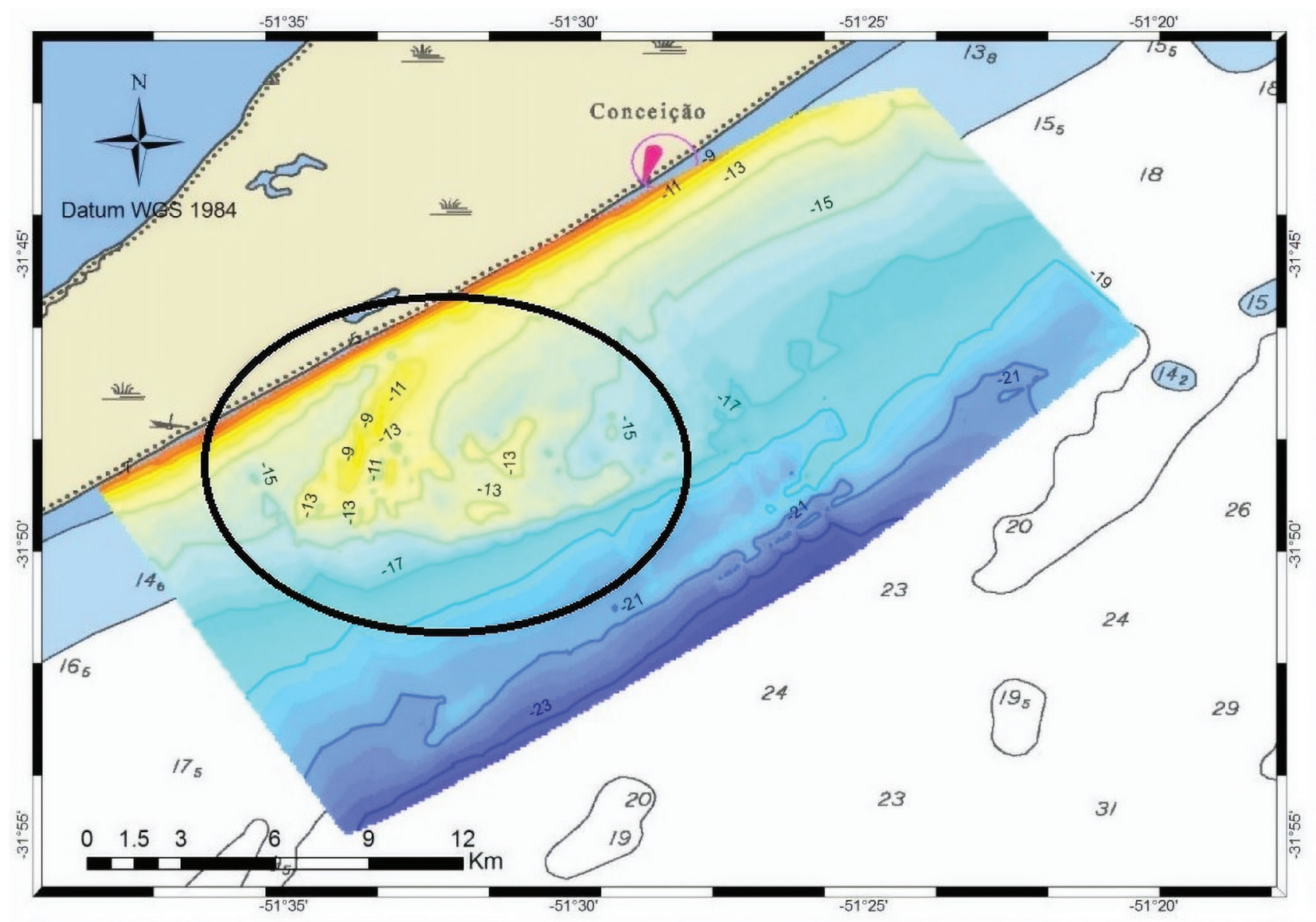

Figura 4. Mapa da batimetria da região do Farol da Conceição. O círculo preto é a localização do Banco Capela, onde apresenta as menores profundidades.

Figure 4. Bathymetric map of the Conceição Lighthouse region. The black circle is the location of Banco Capela, where it has the lowest depths.

a área de voo foi delimitada através do site DroneDeploy, sendo ela de $621 \times 600 \mathrm{~m}^{2}$ com uma altura de voo de $50 \mathrm{~m}$, registrando 832 fotos $(1,87 \mathrm{~cm} /$ pix $)$.

Os dados de altitude adquiridos pelo RTK foram pós-processados e corrigidos usando a ondulação geoidal (diferença entre a ondulação elipsoidal e o geoide), esta correção foi feita utilizando o programa MAPGEO, disponível no site do Instituto Brasileiro de Geografia e Estatística (IBGE).

\subsubsection{O Modelo - Random Shoreface Translation Model}

Com as mudanças climáticas previstas, os fatores costeiros de larga escala (décadas a milênios) serão afetados, sendo eles relacionados ao nível médio do mar, clima de onda e BS (Cowell etal., 2006). Os mesmos autores apontam que tais fatores são difíceis de ser mensurados, levando a incertezas de como prever o comportamento da LC. As incertezas estão relacionadas com cinco fatores os quais influenciam na evolução costeira: as mudanças climáticas, a variação do nível do mar, o clima de ondas, o BS, e também a própria simulação(Cowell et al., 2006).

Neste caso, segundo Cowell et al. (2006), para calcular a variação da LC em relação a mudança climática, esta deve ser através do uso de modelos estocásticos. Estes modelos são capacitados a imitar a aleatoriedade do sistema real através de distribuições probabilísticas, as quais representam matematicamente as chances de ocorrência de todos os valores possíveis para um determinado processo do sistema.

Já os modelos determinísticos não são indicados nos estudos de evolução costeira de larga escala, uma vez que apresentam um conjunto de dados de entrada conhecido e da qual resultará um único conjunto de saída, que muitas vezes não representa a realidade. 


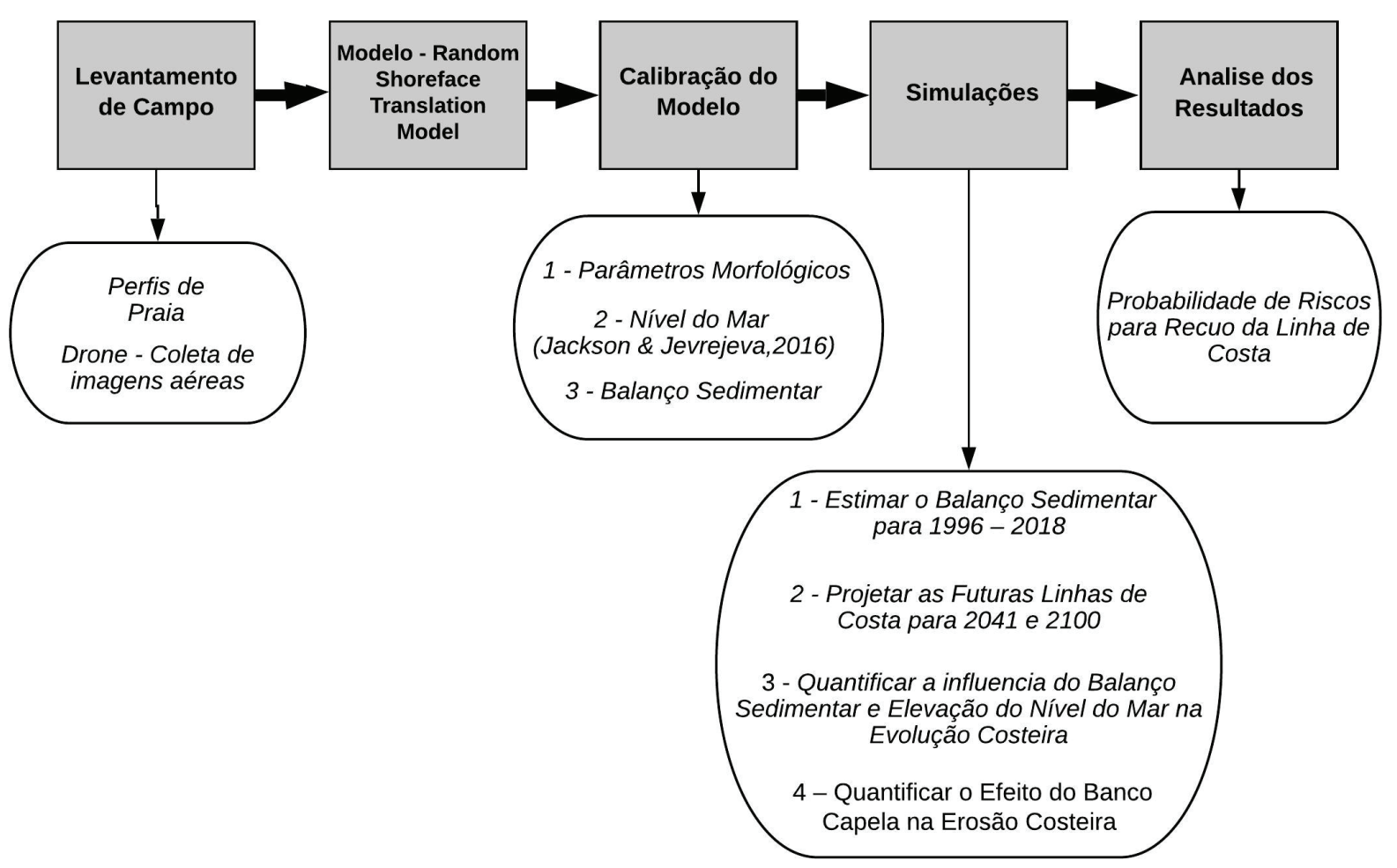

Figura 5. Fluxograma da metodologia aplicada.

Figure 5. Flowchart of the applied methodology.

Diversos pesquisadores ressaltam que, o uso de modelo determinístico para estudar a evolução costeira está no modo como o modelo é usado e não no modelo em si (Pilkey et al., 1993; Cooper \& Pilkey, 2004; Nicholls \& Stive, 2004).

Em vista disso, optou-se pelo uso do modelo estocástico Random Shoreface Translation Model (RanSTM) para simular a variação da LC. O RanSTM permite transformar incertezas relacionadas aos parâmetros de entrada em riscos de probabilidade, através da aplicação da função densidade de probabilidade (FDP) para cada parâmetro de entrada, gerando um único valor de saída. O FDP descreve a probabilidade relativa de uma variável aleatória tomar um valor.

Os valores de saída do modelo representam os possíveis deslocamentos da LC, através dos valores assumidos pela FDP para cada parâmetro de entrada (parâmetros geométricos, nível do mar e BS). Os valores dos parâmetros de entrada do modelo podem assumir valores entre mínimos, máximos e modais, e são referentes a trabalhos anteriores e dados de campo.

o RanSTM se baseia no princípio de conservação de massa e nas regras que controlam o comportamento da barreira (Cowell et al., 2003a, 2003b). Segundo Roy et al. (1995), os principais fatores que controlam a evolução de uma barreira arenosa dominada por onda são: a declividade do substrato, o BS e a variação do nível do mar, sendo estas as variáveis mais importantes e sensíveis do modelo (Cowell et al., 1995, 2003a, 2003b).

O modelo simula a variação da LC através do deslocamento horizontal e vertical da antepraia. A equação 1 representa o deslocamento da LC (R) em função das variações do nível do mar, $S(t)$, dos parâmetros geométricos do substrato, $\mathrm{P}(\mathrm{t})$, e do balanço de sedimento, BS (t).

$$
R=f\left(\frac{d S}{d t}, \frac{d P}{d t}, \frac{d B S}{d t}\right)
$$

Onde $\frac{d P}{d t}$ é representado pela equação 2, a qual mostra os parâmetros morfológicos variando em função do tempo, $P(t)$.

$$
P(t)=\left\{m b, L b, h b, m^{*}, L^{*}, h^{*}, d, L T Z, L R\right\}
$$


Onde $\mathrm{mb}$ é o expoente adimensional da antepraia superior, Lb a largura da antepraia superior, hb a profundidade de fechamento da antepraia superior, $m^{*} \mathrm{o}$ expoente adimensional da antepraia inferior, $L^{*}$ a largura da antepraia inferior, $h^{*}$ a profundidade de fechamento da antepraia inferior, d o parâmetro de dilatação, LTZ a largura da zona de transição entre a antepraia inferior e superior, LR a largura da barreira.

O $\frac{d B S}{d t}$ é calculado através da equação 3 :

$$
B S=V S+V m
$$

Onde: $V_{s}$ representa o ganho e perda de sedimento da antepraia e $\mathrm{Vm}$ representa o suprimento de sedimento da barreira.

\subsubsection{Parâmetros geométricos de entrada - substrato}

\subsubsection{Topografia}

Foi gerado um Modelo Digital de Terreno (MDT) devido à necessidade de ter a topografia da costa com alta resolução espacial e precisão vertical. O MDT vem sendo amplamente utilizado em vários estudos para a reconstrução tridimensional do ambiente (Mancini et al., 2013; Scarelli et al., 2016, 2017). Entre estes estudos, a geomorfologia requer informações topográficas precisas para estudar a costa com o intuito de simular a erosão, identificar áreas de inundação e avaliar o BS (Mancini et al., 2013).

Portanto para construção do MDT (Fig. 6 e 7) foram usadas as imagens obtidas pelo VANT e processadas no programa Agisoft Metashape Professional, que se baseia no algorítmico Structure From Motion (SfM). Basicamente o algorítmico permite reconstruir o cenário em 3D, a partir de combinações de pontos em comum nas imagens (Long et al., 2016). As etapas do processamento apresentado pelo programa para gerar o MDT é dividido em: (1) alinhamento das imagens; nesta fase os pontos em comum das imagens são identificados e alinhados, e também os parâmetros da câmera são calibrados; (2) identificação dos 25 PC nas imagens e inserido as coordenadas de cada um manualmente (Fig. 7A), para uma melhor precisão no georreferenciamento das imagens, para a construção da nuvem densa de pontos (dense point cloud); (3) criação de uma malha 3D que representa a superfície do terreno; (4) aplicação de uma máscara na malha 3D baseada nas elevações dos PC para eliminar qualquer 'ruído' da elevação da superfície do terreno (ex., retirada da vegetação); (5) o MDT é calculado através da interpolação dos pontos da topografia em uma grade regular.

\subsubsection{Batimetria}

Os dados batimétricos usados são referentes ao trabalho de Goulart (2010) (Fig. 8A). A região foi dividida em três setores baseados nas características morfológicas: setor nomeado de Célula Costeira (CC) abrange toda região da batimetria (Fig. 2C); a sub-célula Banco Capela (BC) contem um banco na antepraia (Fig. 8A, retângulo amarelo); e a sub-célula Farol da Conceição (FC) é caracterizado por não conter nenhuma feição morfológica na antepraia (Fig. 8A). Os valores de declividades encontrados foram de $0,091^{\circ}$ para o $\mathrm{BC}$ e 0,10 para o setor FC.

\subsubsection{Processamentos e calibração dos perfis topográficos e batimétricos}

Os dados de topografia e de batimetria foram processados no ArcGIS ${ }^{\text {TM }}$ para a obtenção dos perfis médios, seguindo a metodologia dos trabalhos de Daley (2005) e Figueiredo (2011). Dessa forma, os perfis médios batimetricos foram unidos com o perfil médio topográfico (Fig. 8B), utilizando o programa Excel. Ambos os dados estão relacionadas ao datum do IBGE em relação ao nível do mar.

Os limites morfológicos superior e inferior dos perfis médios, sendo eles a profundidade de fechamento da antepraia superior $\left(h_{b}\right)$ e inferior $\left(h_{\star}\right)$, foram determinados de duas maneiras: primeiro através equações (Eq. 4 e 5) de Hallermeier (1980).

$$
h_{b} \cong 2 \bar{H}_{s}+11 \sigma
$$




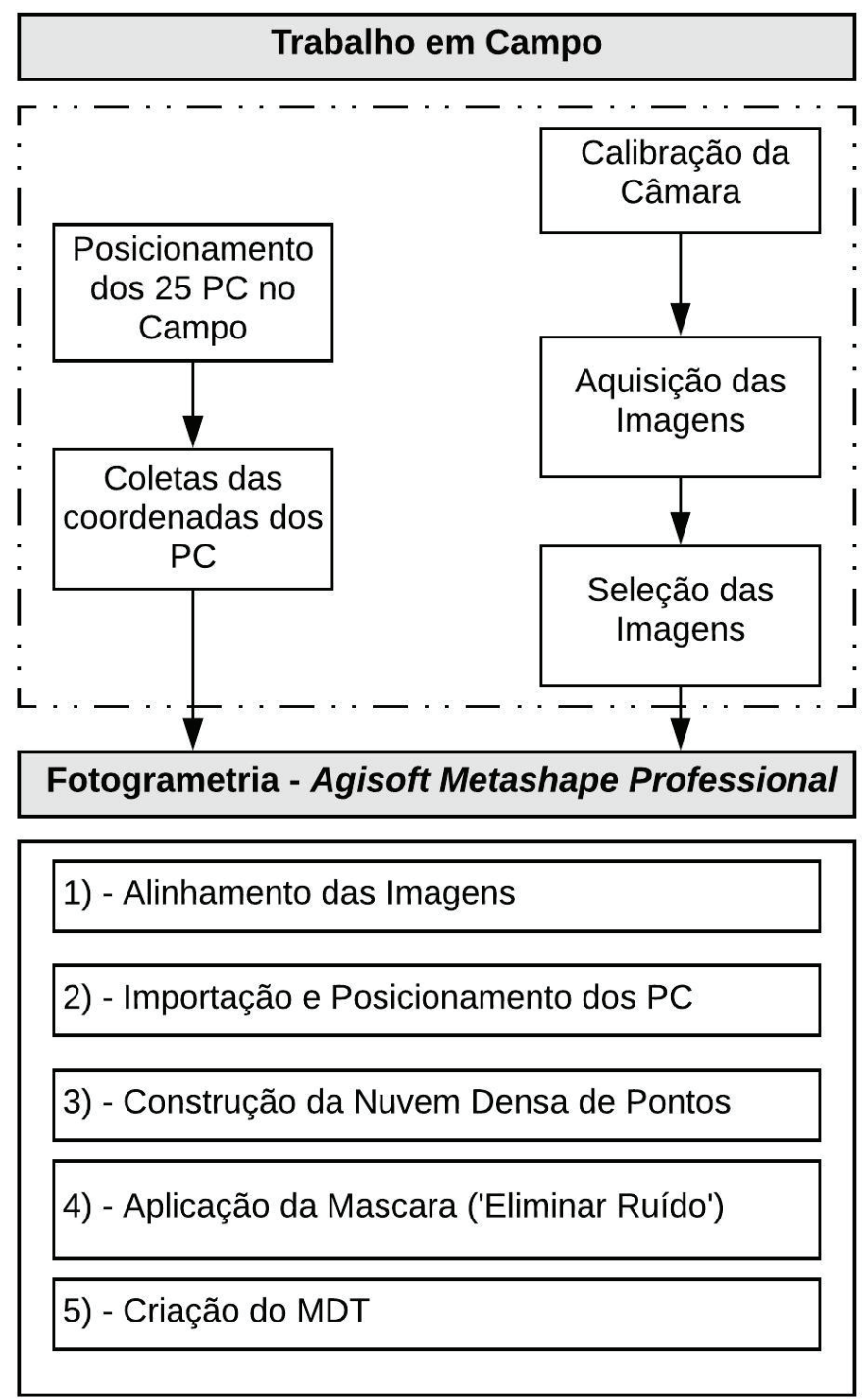

Figura 6. Fluxograma dos métodos aplicados para gerar o Modelo Digital de Terreno. Figure 6. Flowchart of the methods applied to generate the Digital Terrain Model

$$
h_{*} \cong\left(\bar{H}_{s}-0,3 \sigma\right) \bar{T}_{s}(g / 5000 D)^{0,5}
$$

Onde $\bar{H}_{s}$ é a altura média significativa de onda e o desvio padrão da altura significativa, $\bar{T}_{s}$ é o período médio significativo das ondas, $g$ é a gravidade e $D$ é o tamanho médio do sedimento a uma profundidade de $1,5 \times h_{b}$. Os dados para altura de onda e período foram obtidos do site Rede Ondas (https://redeondas.furg.br/pt/), para o período de 2006 a 2016. O valor de $D$ é referente do trabalho de Goulart (2010), caracterizado como areia muito fina. Os valores encontrados para $h_{b}$ e $h_{*}$ foram de -8 e $-26 \mathrm{~m}$ para todos os perfis.

O outro método aplicado para identificar os limites superior e inferior, foi através da quebra da declividade do perfil. Portanto, os valores considerados para $h_{b}$ e $h_{*}$ para os perfis foram de -8 e -20 m, valores assumidos como parâmetro de entrada para o modelo. Foi assumido este método devido a serie temporal dos dados de onda e a escala temporal do trabalho que é de décadas. Hands (1983) aponta que para uma escala de décadas a profundidade de fechamento da antepraia superior e inferior estão relacionados a eventos extremos de altura de onda, enquanto que, as equações 4 e 5 consideram apenas clima de onda anual para encontrar os limites.

\subsubsection{Simulações}

Para este estudo, foram realizadas 18 simulações (Fig. 9) com o modelo RanSTM e cada simulação apresenta 1000 resultados possíveis 


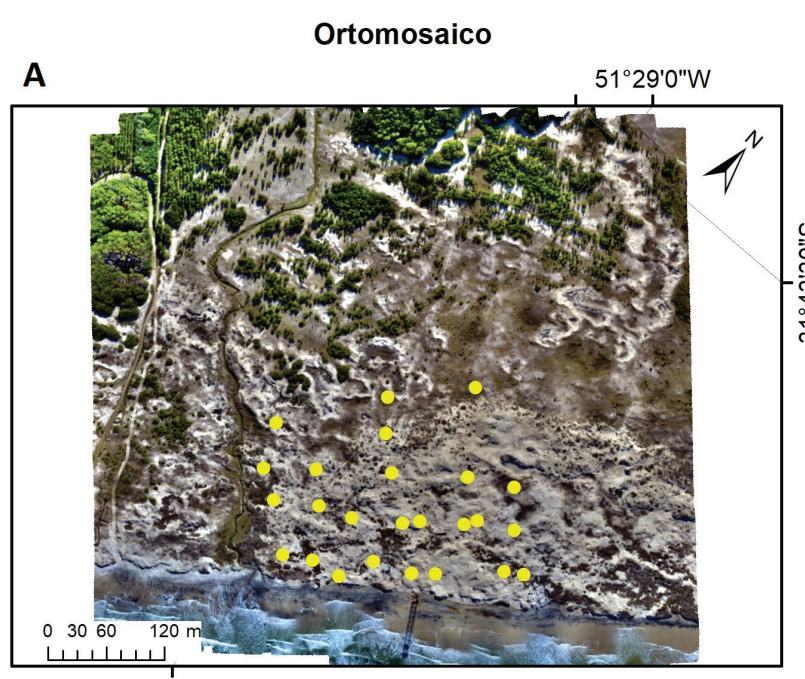

$51^{\circ} 29^{\prime} 0^{\prime \prime W}$

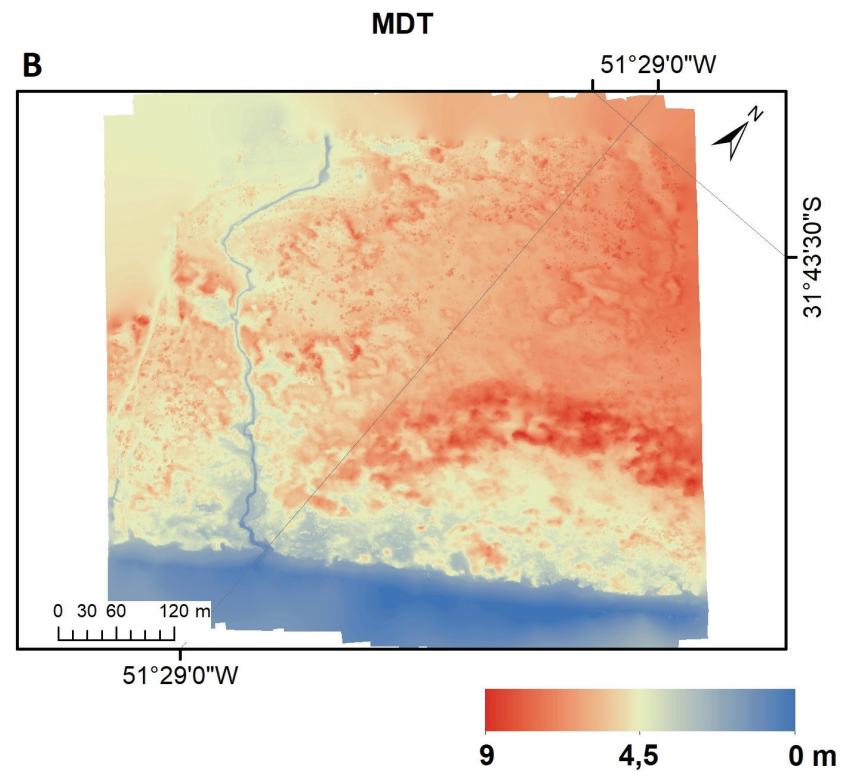

Figura 7. Modelo Digital de Terreno. A) Representa o ortomosaico da região do Farol da Conceição com os 25 pontos de controle (pontos amarelos); B) Modelo Digital de Terreno.

Figure 7. Digital Terrain Mode (DTM)). A) Represents the orthomosaic of Conceição Lighthouse region with 25 control points (yellow balls); B) Digital Terrain Model.

para o recuo da LC. Segundo Carrasco \& Chang (2005), 1000 soluções é um número ideal para representar a probabilidade da variação da LC, para a escala de tempo do trabalho.

De início o modelo RanSTM foi executado de modo determinístico, para simular o recuo da LC para um período de tempo referente a 23 anos (1996 - 2018), para estimar o BS da Célula Costeira (CC). Considerando a elevação do nível do mar (ENM) de $2 \mathrm{~mm} /$ ano segunda Da Silva et al. (2016).

0 valor encontrado para BS referente ao período de 23 anos foi usado como dado de input para as projeções futuras da LC. Desta forma o modelo foi rodado de modo estocástico para as projeções de 2041 e 2100, onde os valores de ENM variaram randomicamente entre o mínimo, a moda e o máximo (Tab. 1). Os dados de ENM foram obtidos do trabalho de Jackson \& Jevrejeva (2016), que analisaram as probabilidades regionais da variação do nível do mar para o século 21. Sendo assim, os valores assumidos para os anos de 2041 e 2100 , foram: 0,1 (min), 0,1 (moda) e 0,2 (máx) m e 0,5, 0,5 e 1 $\mathrm{m}$, respectivamente.

\subsubsection{Análise estatística}

Para a interpretação dos dados de saída do modelo foram gerados gráficos de probabilidade de excedência. A análise permite calcular a possibilidade de um evento acontecer para um determinado período de tempo, neste caso o recuo da LC. A equação 6 mostra como é feito o cálculo da probabilidade de excedência.

$$
P=100 x(m \div(n+1))
$$

Na equação, $P$ representa a porcentagem de probabilidade do evento de acontecerem, $m$ é ordem dos valores das amostras (decrescente) e $n$ representa o número total de eventos.

\section{Resultados e discussões}

\section{1 Evolução costeira dos últimos 23 anos}

Ao analisar os perfis de praia dos últimos 23 anos (Fig. 10), assumindo a base da duna como indicador da LC, constatou-se um recuo 
A

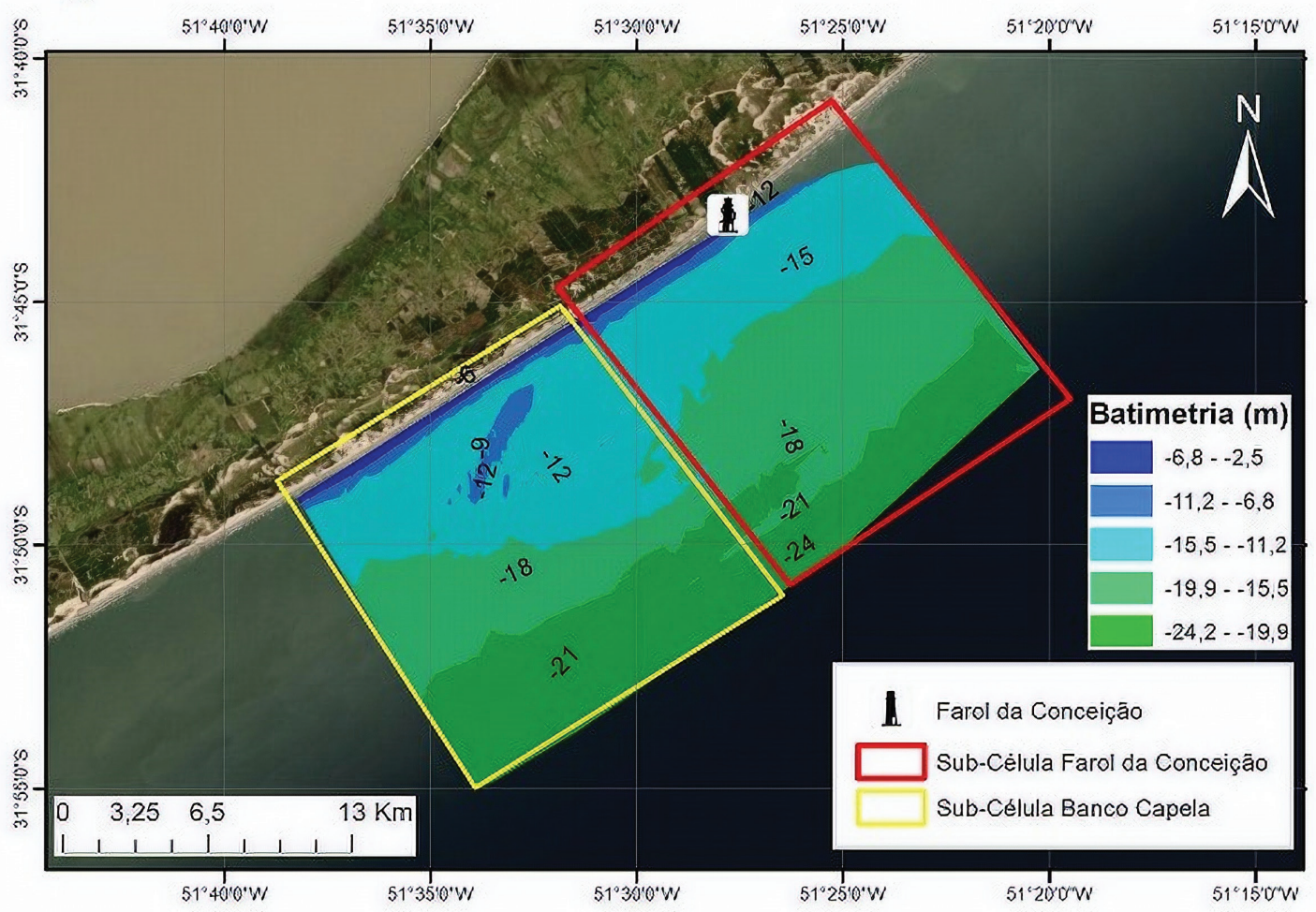

B

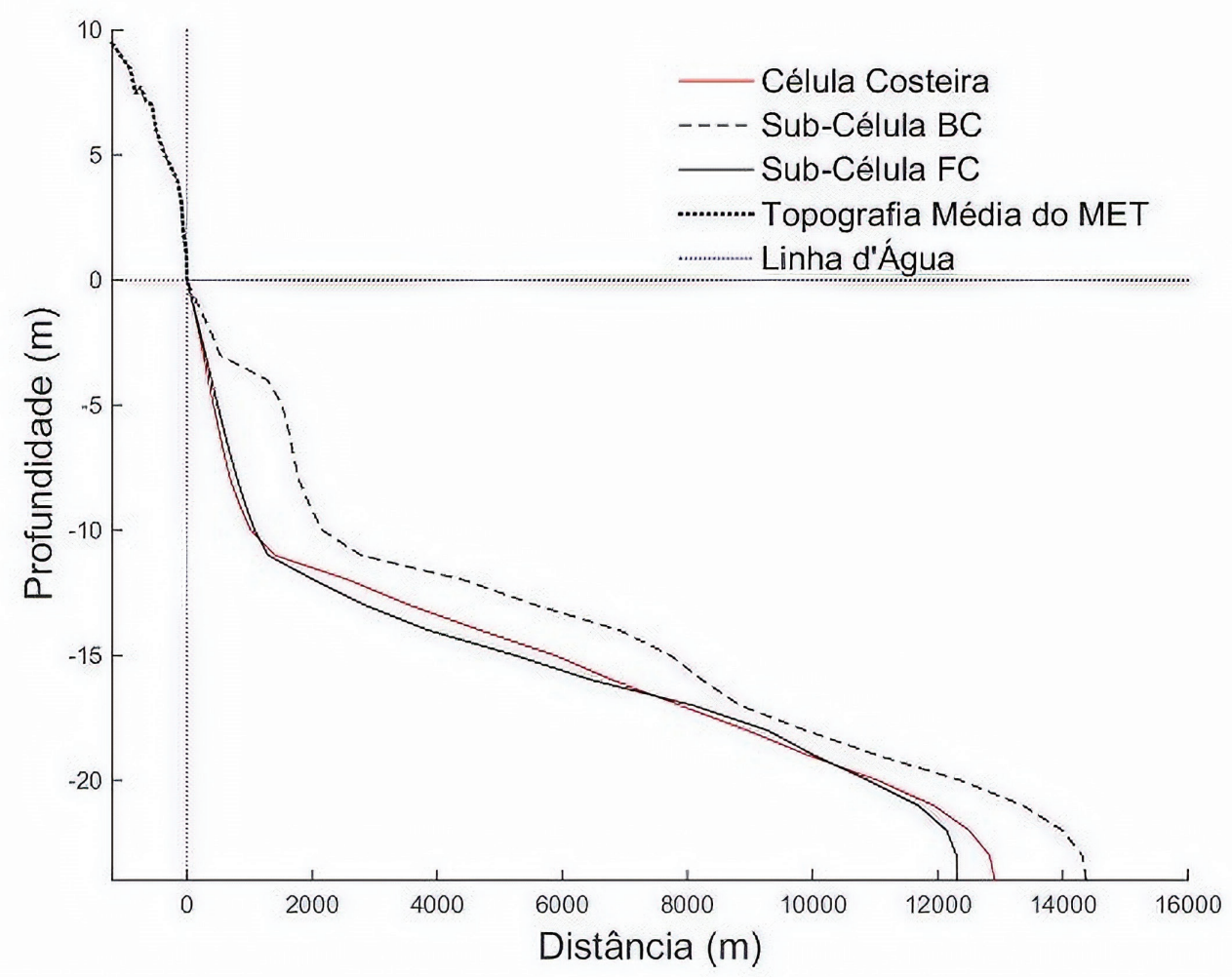

Figura 8. Imagem da área de estudo (fonte: Esri, DigitalGlobe, Earthstar Geographics, CNES/Airbus DS, GeoEye, USDA FSA, USGS, Aerogrid, IGN, IGP, e do GIS User Community) e dos perfis batimétricos. A) Batimetria da região do Bojuru (Goulart, 2010), contendo as Sub-Células Farol da Conceição e Banco Capela; B) Perfis da antepraia referentes à batimetria da Célula Costeira, para cada Sub-Célula, e também a topografia média do MDT.

Figure 8. Image of the study aria (sources: Esri, DigitalGlobe, Earthstar Geographics, CNES/Airbus DS, GeoEye, USDA FSA, USGS, Aerogrid, IGN, IGP, and the GIS User Community) and the Bathymetric profiles. A) Bathymetry of the Conceição Lighthouse region (Goulart, 2010), containing the Sub-Cells Farol da Conceição and Banco Capela; B) Bathymetric profiles of the shoreface for the Coastal Cell, for each Sub-cell and the mean topography of the DTM. 


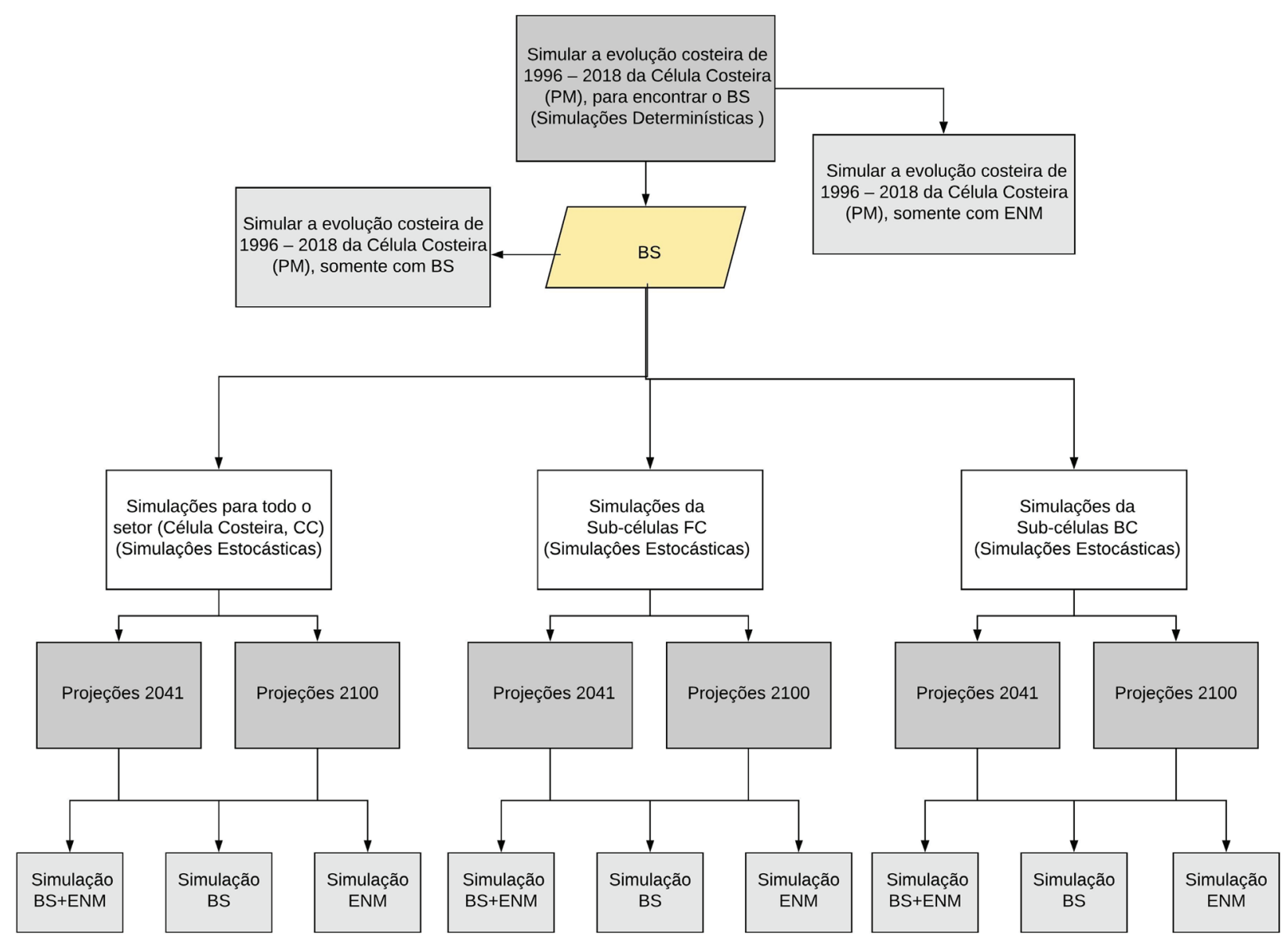

Figura 9. Simulações realizada pelo RanSTM para cada divisão setor. Simulação BS+ENM é a influência das duas variáveis juntas na evolução costeira; simulações BS e ENM representam a influência individual de cada variável na evolução costeira.

Figure 9. RanSTM simulations for it division of the aria. BS + ENM is the simulation of the influence of the two variables on coastal evolution; BS and ENM simulations represent the individual influence of each variable on coastal evolution.

Tabela 1. Valores da elevação do nível do mar e o tipo de simulação.

Table 1. Sea leval rise values and the type of simulation.

\begin{tabular}{cccccc}
\hline & \multicolumn{4}{c}{ Nível do Mar (m) } \\
Período & Simulações & min & moda & max & Referência \\
\hline $1996-2018$ & Determinística & 0,046 & 0,046 & 0,046 & Da Silva et al. (2016) \\
$2018-2041$ & Estocástica & 0,1 & 0,1 & 0,2 & Jackson \& Jevrejeva (2016) \\
$2018-2100$ & Estocástica & 0,5 & 0,5 & 1 & Jackson \& Jevrejeva (2016) \\
\hline
\end{tabular}

de 68 m a uma taxa de -2,96 m/ano. Diversos trabalhos foram realizados na região do Farol da Conceição procurando entender o padrão do recuo da LC, através do deslocamento dos perfis de praia ao longo dos anos. As taxas de recuo encontradas foram de $-3,6 \mathrm{~m} / \mathrm{ano}$ entre os anos de 1996 e 1999 (Barletta \& Calliari, 2003), -3,7 m/ ano de 1996 a 2006 (Pereira et al., 2007) e -4,37 m/ano de 1996 a 2012 (Machado, 2014).

Dillenburg et al. (2000) simularam a evolução costeira de larga escala do RS dos últimos $5 \mathrm{ka}$ anos, usando o modelo Shoreface
Translation Model (STM), encontrando para a região um recuo da LC de 2,5 km à uma taxa de $-0,5 \mathrm{~m} / \mathrm{ano}$.

A simulação da evolução costeira de 1996 a 2018 demonstrou que a área apresenta um déficit de sedimento de $-1000 \mathrm{~m}^{3} / \mathrm{m}$ correspondendo aproximadamente $-2,6 \times 10^{6} \mathrm{~m}^{3}$ ao longo de 26 $\mathrm{km}$ de LC. Motta et al. (2015) encontraram para o período de 1998 a 2009 um déficit de sedimento $-4,8 \times 10^{6} \mathrm{~m}^{3}$ na região utilizando dados de deriva litorânea, para estimar o BS. 


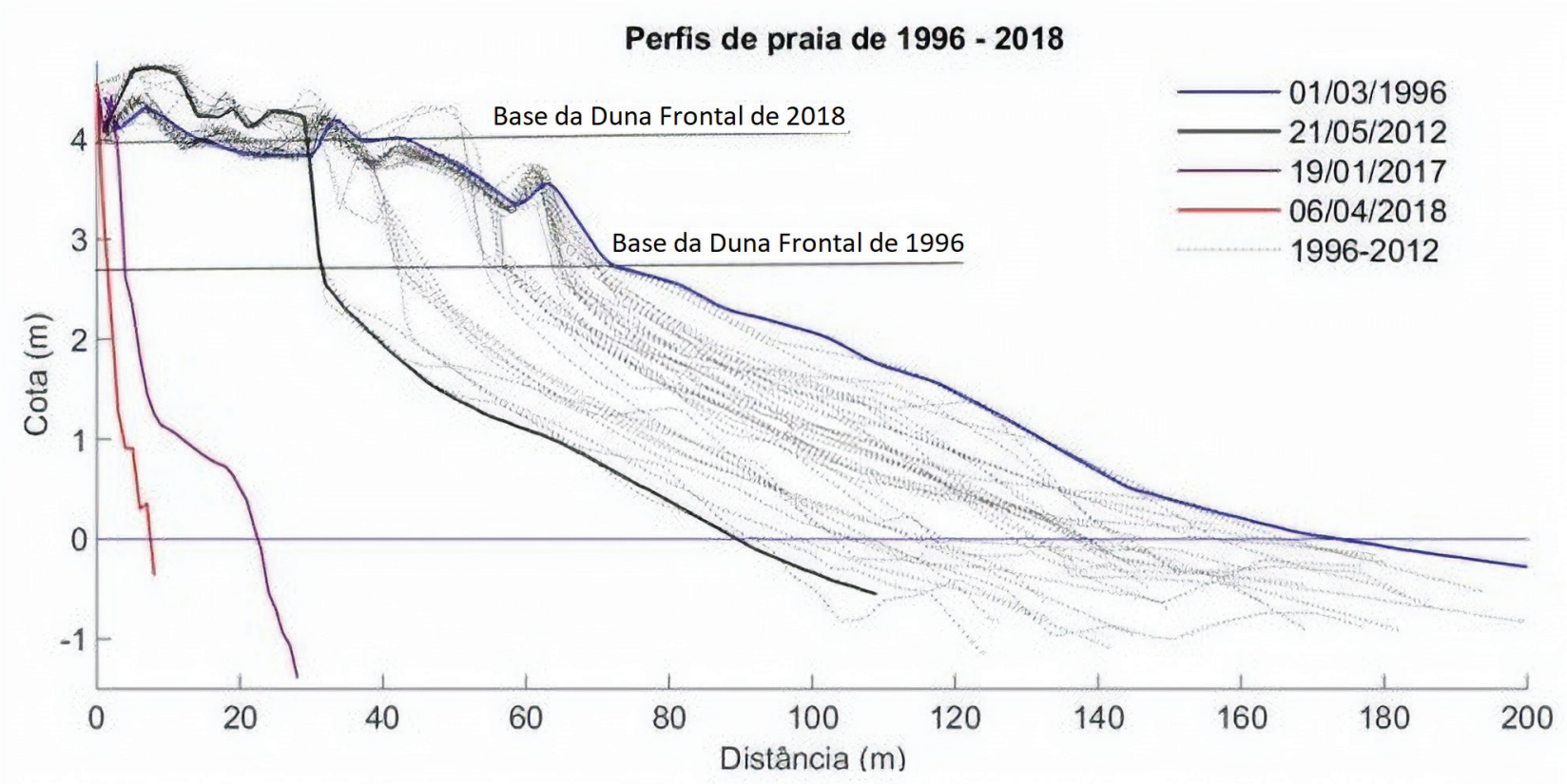

Figura 10. Perfis de praia de 1996 a 2018, que mostram um recuo de 68 m da LC (fonte: Laboratório de Oceanografia Geológica da Universidade Federal do Rio Grande).

Figure 10. Beach profiles from 1996 to 2018 showing a retreat of 68 m of the coast line (sources: Geological Oceanography Laboratory from the University of Rio Grande).

\subsection{Projeções das futuras linhas de costa para 2041 e 2100}

Para a CC, as simulações realizadas para as projeções futuras da LC para 2041 e 2100 (Tab. 2 e as Fig. 11A e B) mostraram que o setor tem 50\% de risco de apresentar um recuo de 92,2 $\mathrm{m}$, a uma taxa de $-4,01 \mathrm{~m} /$ ano para 2041, e para 2100 , o recuo seria de 359,2 m, a uma taxa de $-4,38 \mathrm{~m} / a n$. Estas taxas se aproximam dos valores encontrados por Barletta \& Calliari (2003), Pereira et al. (2007) e Machado (2014) descritos anteriormente.

Figueiredo (2013) usou o modelo RanSTM para simular os efeitos da ENM no litoral do RS, baseado nos dados de ENM do IPCC de 2007. Desta forma, encontrou para os anos de 2030, 2070 e 2100, um recuo médio da LC de 73, 209 e $316 \mathrm{~m}$, a taxas de -3,7,-3,5 e -3,5 m/ano, respectivamente.

As simulações feitas para os anos 2041 e 2100 , realizadas para cada sub-célula, mostraram comportamentos diferentes de regressão da LC (Tab. 3 e 4), sendo que as maiores taxas de recuo foram encontradas na sub-célula BC. Os valores encontrados para cada projeção foram de -4,55 e -5,07 m/ano, para a sub-célula BC, e -3,85 e -4,23 m/ano, para a sub-célula FC.

As diferentes taxas de erosão encontradas entre as sub-células (Fig. 11 C, D, E e F) estão relacionadas com a declividade do substrato. Diversos pesquisadores (Roy et al., 1995; Dillenburg et al., 2000; Figueiredo, 2011) apontam que a diferença na declividade da batimetria produz variações nas taxas de deslocamento da LC. Desta forma, a sub-célula BC, a qual contém o Banco Capela, apresentou a menor declividade e as maiores taxas de erosão por ano em relação à sub-célula FC, a qual apresentou a maior declividade e as menores taxas de erosão. Figueiredo (2013) encontrou o mesmo padrão de erosão para a praia do Cassino (menor declividade) e para o Farol da Conceição (maior declividade), analisando a evolução costeira para os anos de 2030, 2070 e 2100. A praia do Cassino recuou mais quando comparada ao setor do Farol da Conceição, cujas declividades da antepraia são $0,027^{\circ}$ e $0,070^{\circ}$ para cada região, respectivamente (Dillenburg et al., 2000). 
Tabela 2. Valores de distâncias e taxas de recuo para 50 e 1\% de risco, para 2041 e 2100, para a Célula Costeira. Table 2. Distance values and retreat rates for 50 and 1\% risk, for 2041 and 2100 for the Coastal Cell.

\begin{tabular}{lcccccc}
\hline \multirow{2}{*}{\multicolumn{1}{c}{ Resultados }} & \multicolumn{9}{c}{ Célula Costeira } \\
\cline { 2 - 7 } & \multicolumn{2}{c}{ Total } & \multicolumn{2}{c}{$\begin{array}{c}\text { Balanço } \\
\text { Sedimentar }\end{array}$} & \multicolumn{2}{c}{$\begin{array}{c}\text { Elevação do } \\
\text { Nível do Mar }\end{array}$} \\
\cline { 2 - 7 } & $\mathbf{2 0 4 1}$ & $\mathbf{2 1 0 0}$ & $\mathbf{2 0 4 1}$ & $\mathbf{2 1 0 0}$ & $\mathbf{2 0 4 1}$ & $\mathbf{2 1 0 0}$ \\
\hline Recuo Médio (m) & 92,20 & 359,20 & 52,70 & 176,40 & 42,70 & 193,20 \\
Taxa de Recuo Médio (m/ano) & 4,01 & 4,38 & 2,29 & 2,15 & 1,86 & 2,36 \\
1\% de Risco (m) & 117,22 & 487,61 & 57,20 & 189,30 & 74,20 & 336,76 \\
Taxa de Recuo referente a 1\% (m/ano) & 5,10 & 5,95 & 2,49 & 2,31 & 3,23 & 4,11 \\
\hline
\end{tabular}

Tabela 3. Valores de distâncias e taxas de recuo para 50 e 1\% de risco, para 2041 e 2100, para a Sub - Célula FC. Table 3. Distance values and retreat rates for 50 and 1\% risk, for 2041 and 2100 for the sub-cell FC.

\begin{tabular}{lcccccc}
\hline \multirow{2}{*}{\multicolumn{1}{c}{ Resultados }} & \multicolumn{5}{c}{ Sub - Célula FC } \\
\cline { 2 - 7 } & \multicolumn{2}{c}{ Total } & \multicolumn{2}{c}{$\begin{array}{c}\text { Balanço } \\
\text { Sedimentar }\end{array}$} & \multicolumn{2}{c}{$\begin{array}{c}\text { Elevação do } \\
\text { Nível do Mar }\end{array}$} \\
\cline { 2 - 7 } & $\mathbf{2 0 4 1}$ & $\mathbf{2 1 0 0}$ & $\mathbf{2 0 4 1}$ & $\mathbf{2 1 0 0}$ & $\mathbf{2 0 4 1}$ & $\mathbf{2 1 0 0}$ \\
\hline Recuo Médio (m) & 88,60 & 347,10 & 50,50 & 172,40 & 40,50 & 186,40 \\
Taxa de Recuo Médio (m/ano) & 3,85 & 4,23 & 2,20 & 2,10 & 1,76 & 2,27 \\
1\% de Risco (m) & 114,10 & 472,65 & 55,50 & 186,30 & 70,72 & 335,93 \\
Taxa de Recuo referente a 1\% (m/ano) & 4,96 & 5,76 & 2,41 & 2,27 & 3,07 & 4,10 \\
\hline
\end{tabular}

Tabela 4. Valores de distâncias e taxas de recuo para 50 e 1\% de risco, para 2041 e 2100, para a Sub - Célula BC. Table 4. Distance values and retreat rates for 50 and 1\% risk, for 2041 and 2100 for the sub-cell BC.

\begin{tabular}{lcccccc}
\hline \multirow{2}{*}{\multicolumn{1}{c}{ Resultados }} & \multicolumn{5}{c}{ Sub - Célula BC } \\
\cline { 2 - 7 } & \multicolumn{2}{c}{ Total } & \multicolumn{2}{c}{$\begin{array}{c}\text { Balanço } \\
\text { Sedimentar }\end{array}$} & \multicolumn{2}{c}{$\begin{array}{c}\text { Elevação do } \\
\text { Nível do Mar }\end{array}$} \\
\cline { 2 - 7 } & $\mathbf{2 0 4 1}$ & $\mathbf{2 1 0 0}$ & $\mathbf{2 0 4 1}$ & $\mathbf{2 1 0 0}$ & $\mathbf{2 0 4 1}$ & $\mathbf{2 1 0 0}$ \\
\hline Recuo Médio (m) & 104,60 & 415,40 & 52,70 & 176,20 & 54,10 & 251,90 \\
Taxa de Recuo Médio (m/ano) & 4,55 & 5,07 & 2,29 & 2,15 & 2,35 & 3,07 \\
1\% de Risco (m) & 131,30 & 568,94 & 57,80 & 191,20 & 89,52 & 409,55 \\
Taxa de Recuo referente a 1\% (m/ano) & 5,71 & 6,94 & 2,51 & 2,33 & 3,89 & 4,99 \\
\hline
\end{tabular}

3.3 Efeito do balanço sedimentar e da elevação do nível do mar no recuo da linha de costa

As simulações independentes feitas para cada variável (BS e ENM) foram realizadas com o intuito de quantificar o efeito de cada uma no recuo da LC (Fig. 9), desta forma, identificando qual a principal componente da evolução costeira nos últimos 23 anos, e também, para as projeções de 2041 e 2100.

Dillenburg et al. $(2000,2003,2004)$ apontam que a evolução costeira do RS durante os últimos
5 ka foi conduzida, sobretudo, pelo BS, quando o nível do mar estava abaixando. Figueiredo et al. (2018) usando os dados de ENM atuais, demonstraram que o BS corresponde a $58 \%$ da erosão da região da praia do Hermenegildo, RS. O mesmo padrão descrito pelos autores foi encontrado na simulação da evolução costeira entre 1996 a 2018 (Tab. 5), no entanto para um cenário de ENM. As taxas médias de recuo da LC para a CC são -2,38 m/ano (recuo de 54,7 m) para o BS, e -0,67 m/ano (15,4 m de recuo) para a ENM. 

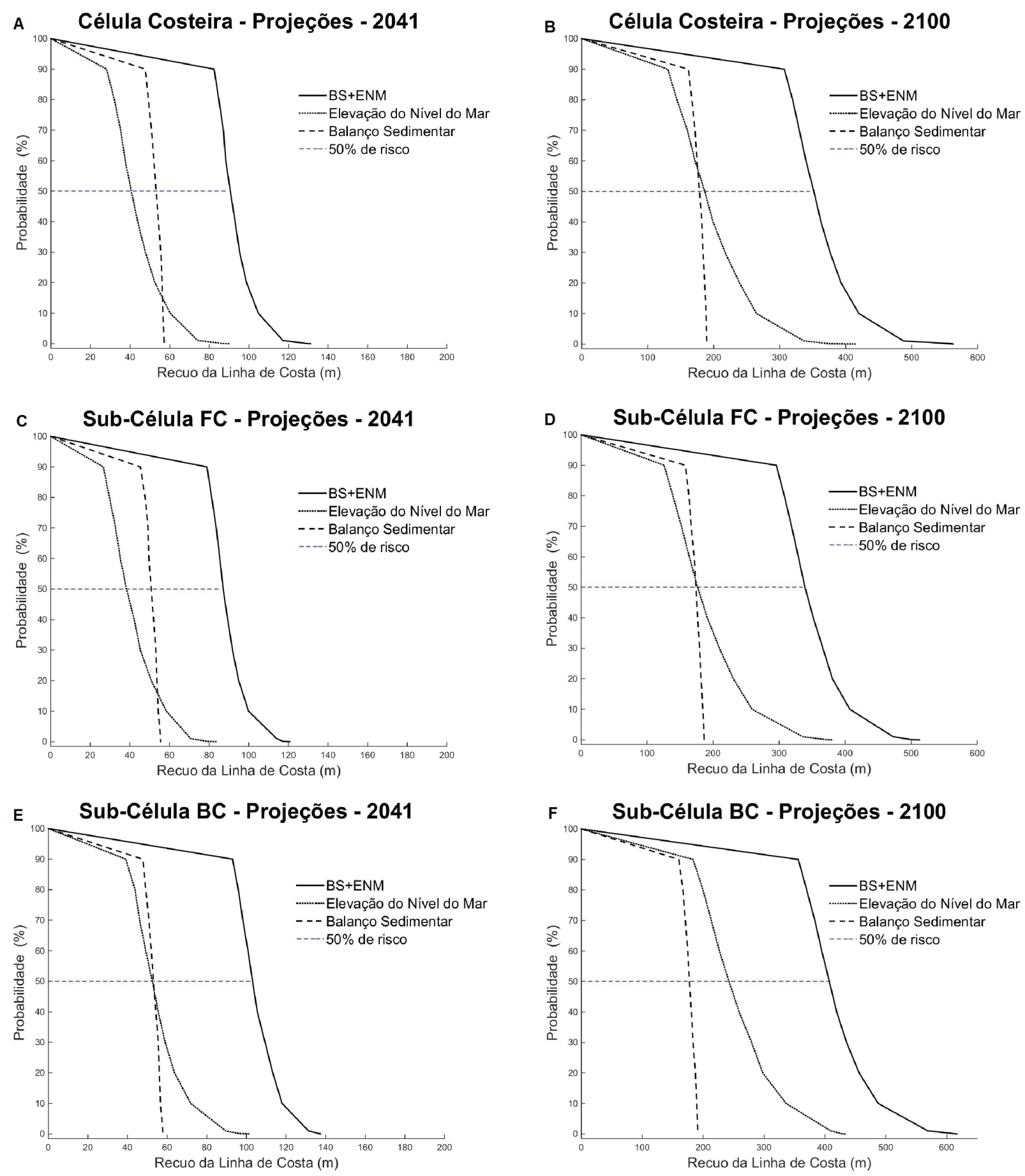

Figura 11. Resultados de probabilidade de recuo da LC para 2041 e 2100 . A) Para 2041 do setor CC; B) Para 2100 do setor CC; C) Para 2041 da sub-célula FC; D) Para 2100 da sub-célula FC; E) Para 2041 da sub-célula BC; F) Para 2100 da sub-célula BC.

Figure 11. Shoreline retreat probability for 2041 and 2100. A) Shoreline for 2041 for CC region; B) Shoreline for 2100 for CC region; C) Shoreline for 2041 for sub-cell FC; D) Shoreline for 2100 for sub-cell FC; E) Shoreline for 2041 for sub-cell $B C$; F) Shoreline for 2100 for sub-cell BC. 
Tabela 5. Valores de distâncias e taxas de recuo, para risco de 50\%, dos últimos 23 anos.

Table 5. Distance values and retreat rate for $50 \%$ of risk, for the last 23 years.

\begin{tabular}{l|c|cc}
\hline \multirow{2}{*}{ Resultados } & \multicolumn{2}{c}{ Simulação da Evolução Costeira de 1996-2018 } \\
\cline { 2 - 4 } & \multirow{2}{*}{ Total } & $\begin{array}{c}\text { Balanço } \\
\text { Sedimentar }\end{array}$ & $\begin{array}{c}\text { Elevação do Nível do } \\
\text { Mar }\end{array}$ \\
\hline Recuo Médio (m) & 68 & 54,70 & 15,4 \\
Taxa de Recuo Médio (m/ano) & 2,95 & 2,38 & 0,67 \\
\hline
\end{tabular}

Estudos mostram que setores costeiros em que a ENM corresponde às médias globais, outros processos são mais relevantes no recuo da LC, como por exemplo, o transporte de sedimentos (Webb \& Kench, 2010; Ford, 2013). No entanto, outras pesquisas, mostraram que onde ENM é significativamente diferente das médias globais, como por exemplo, na costa leste dos EUA (Zhang et al., 2004; Gutierrez et al., 2011), nas praias do Havaí (Romine et al., 2013), da PapuaNova Guiné (Shearman et al., 2013) e da Europa (Le Cozannet et al., 2014), existe uma forte relação entre variação do nível do mar e variação da LC. Além disso, o efeito acelerado da ENM pode ser mascarado por outros processos relacionados a eventos de tempestades, correntes ao longo da praia e pela influência antropogênicos, é o que está acontecendo no Pacífico Ocidental (Le Cozannet et al., 2013)

As projeções realizadas para toda região (CC) demonstraram que o BS negativo é a principal componente do recuo da LC para 2041 (Tab. 2 e Fig. 11A). Este resultado pode ser explicada pelos trabalhos de Lima et al. (2001) e Motta et al. (2015), que analisaram o transporte de sedimento longitudinal e o BS para o litoral médio do RS, encontrando as maiores taxas de transporte e déficit de sedimento na região do Farol da Conceição; e segundo Dillenburg et al. (2000) e Martinho et al. (2009), estes valores estão relacionados com a alta declividade da plataforma continental e a alta energia de onda da região, acarretando maiores velocidades de transporte de sedimentos para fora do setor, criando, consequentemente, um déficit de sedimentos ou BS negativo. Além disso, List et al. (1997) e Sallenger et al. (2012) ao estudarem a evolução das barreiras da Louisiana nos Estados Unidos, apontaram que o BS pode ser a principal componente da evolução costeira ao mesmo passo em que ocorre uma lenta ENM.

No entanto, as projeções para 2100 mostram que a ENM passa a ser a principal componente do recuo da LC (Tab. 2 e Fig. 11B), devido a maiores taxas de ENM esperado para 2100. Figueiredo et al. (2018) simularam o efeito individual da ENM e do BS na praia do Hermenegildo para 2100, usando os dados do IPCC para ENM, RCP 2,6 (menor taxa de ENM) e RCP 8,5 (maior taxa de ENM), constataram que a ENM passa a controlar a e evolução costeira, correspondendo a 79 e $85 \%$ do recuo da LC respectivamente.

Em relação às sub-células FC e CC, as projeções para 2041 demonstraram que para o setor FC (Tab. 3), a principal componente da erosão é o BS, apresentando uma taxa de recuo médio maior comparado à taxa apresentada pela ENM, sendo estas, $-2,2 \mathrm{~m} / \mathrm{ano}$ ( $50,5 \mathrm{~m}$ de recuo) e $-1,76 \mathrm{~m} / \mathrm{ano}$ (40,5 $\mathrm{m}$ de recuo), respectivamente. No entanto, para o setor BC (Tab. 4) a principal componente é a ENM, porem as duas variáveis apresentaram a mesma relevância para a evolução costeira, apresentando valores semelhantes entre as taxas médias de recuo da LC, $-2,29 \mathrm{~m} / \mathrm{ano}(52,7 \mathrm{~m}$ de recuo) para BS, e $-2,35 \mathrm{~m} / \mathrm{ano}(54,1 \mathrm{~m}$ de recuo) para ENM.

As simulações feitas para 2100 indicaram que a componente principal é a ENM para ambas as sub-células (Fig. 11D e F.), sendo que no setor FC, as taxas médias não apresentaram diferenças significativas entre ENM e BS, apresentando os respectivos valores $-2,27 \mathrm{~m} /$ ano (186,4 m de recuo) e -2,1 m/ano (172,4 m de recuo). Isto indica que as duas variáveis têm a mesma relevância na evolução deste setor. Para a sub-célula $\mathrm{BC}$, os valores encontrados foram de $-3,07$ m/ano (251,9 $\mathrm{m}$ de recuo) para ENM, e 


\section{2,38 m/ano (179,2 m de recuo) para BS.}

As diferenças entre os resultados para as sub-células refletem a variação da declividade e do comprimento da antepraia entre os setores, principalmente para as projeções de 2100. Dillenburg et al. (2000) e Figueiredo (2013) apontam que, sob o efeito da ENM, as regiões com as menores declividades na antepraia apresentam as maiores taxas de recuo. 0 mesmo padrão é observado entre as sub-células, em que as maiores taxas de recessão da LC estão na sub-célula BC que apresenta a menor declividade (Fig. 11F e Tab. 4).

Ao observar os dados de recuo da LC em relação às menores probabilidades de riscos (1\%) para 2041 e 2100, mostraram que, para CC a principal componente é a ENM (Tab. 2), assim como para as sub-células (Tab. 3 e 4).

\section{Conclusões}

Através da modelagem da evolução costeira sob diferentes cenários de ENM, foi estimado o BS dos últimos 23 anos, que resultou em $68 \mathrm{~m}$ de recuo da LC, também foram projetadas as LC para 2041 (recuo de 92,2 m) e 2100 (recuo de $359,2 \mathrm{~m})$.

Além disso, taxas de recuo da LC foram estimadas para cada componente que influencia sua variação (ENM e BS). Para as condições de ENM atual para o setor CC, a principal causa da recessão da LC é o BS, o mesmo foi encontrado para a projeção de 2041, mas para 2100 a ENM passa a ser a principal componente da evolução. Em relação as sub-células, para FC, a projeção de 2041 aponta que a recessão é dominada pelo BS e em 2100 as duas variáveis tem a mesma relevância. Por outro lado, o setor BC as duas variáveis apresentam a mesma importância na evolução costeira para 2041, mas em 2100 a ENM controla a recessão.

As projeções feitas para as diferentes morfologias da região mostram que o Banco Capela influencia o aumento das taxas de recuo da LC devido à baixa declividade, permitindo um maior avanço do nível do mar continente adentro.

As projeções para 2041 e 2100 mostram que, quando maior as taxas de ENM, maior será a sua influência no recuo da LC no RS, considerando que, o clima de onda e o estoque de sedimento continue o mesmo, sob o efeito da mudança climática prevista para o século XXI.

Agradecimentos. O primeiro autor agradece à Coordenação de Aperfeiçoamento de Pessoal de Nível Superior - CAPES (001) pelo fomento da bolsa de estudos.

\section{Referências}

Alvares, C.A., Stape, J.L., Sentelhas, P.C., Gonçalves, J.L.M. \& Sparovek, G. 2013. Köppen's climate classification map for Brazil. Meteorologische Zeitschrift, 22: 711-728.

Angulo, R.J., Lessa, G.C. \& Souza, M.C. 2006. A critical review of the Mid to Late Holocene sea-level fluctuations on the eastern Brazilian coastline. Quaternary Science Reviews, 25(5): 486-506.

Barboza, E.G., Rosa, M.L.C.C., Hesp, P.A., Dillenburg, S.R., Tomazelli, L.J. \& Ayup-Zouain, R.N. 2011. Evolution of the Holocene coastal barrier of Pelotas Basin (southern Brazil) - a new approach with GPR data. Journal of Coastal Research, SI 64: 646-650.

Barboza, E.G. \& Tomazelli, L.J. 2003. Erosional features of the eastern margin of the Patos Lagoon, southern Brazil: significance for Holocene history. Journal of Coastal Research, 35(SI): 260-264.

Barletta, R.C. \& Calliari, L.J. 2003. An assessment of the atmospheric and wave aspects determining beach morphodynamic characterristics along the central coast of RS state, Southern Brazil. Journal of Coastal Research, 35(SI): 300-308.

Bird, E.C.F. 1996. Coastal erosion and rising sea level. In: Millimann, J.D. \& Haq, B.U. (Ed.). Sea Level Rise and Coastal Subsidence. Dordrecht, the Netherlands, p. 87-103.

Bitencourt, V.J.B., Dillenburg, S.R., Manzolli, R.P. \& Barboza, E.G. 2020. Control factors in the evolution of Holocene coastal barriers in Southern Brazil. Geomorphology, 360: 107180.

Bruun, P. 1962. Sea-level Rise as a Cause of Shore Erosion. Journal of Waterways Harbors Division, 88: 117-130. 
Buchmann, F.S.C. \& Tomazelli, L.J. 2003. Relict nearshore shoals of Rio Grande do Sul, Southern Brazil: Origin and effects on nearby modern beaches. Journal of Coastal Research, 35(SI): 318-322.

Calliari, L.J., Tozzi, H.A. \& Klein, A.H. 1998. Beach Morphology and Coastline Erosion Associated with Storm Surges in the Southern Brazil Rio Grande to Chuí, RS. Anais Da Academia Brasileira de Ciências, 70(2): 231-247.

Carrasco, I.J. \& Chang, S.Y. 2005. Random Monte Carlo simulation analysis and risk assessment for ammonia concentrations in wastewater effluent disposal. Stochastic Environmental Research and Risk Assessment, 19: 134-145.

Carter, R.W.G. \& Woodroffe, C.D. 1994. Late Quaternary shoreline morphodynamics. Cambridge University Press, Cambridge, 517p. Church, J.A., Clark, P.U., Cazenave, A., Gregory, J.M., Jevrejeva, S., Levermann, A., Merrifield, M.A., Milne, G.A., Nerem, R.S., Nunn, P.D., Payne, A.J., Pfeffer, W.T., Stammer, D. \& Unnikrishnan, A.S. 2013. Sea-level rise by 2100 . Science, 42(6165): 1445-1445.

Church, J.A. \& White, N.J. 2011. Sea-level rise from the late 19th to the early 21 st century. Surveys in Geophysics, 32(4-5): 585-602.

Cooper, J.A.G. \& Pilkey, O.H. 2004. Sea-level rise and shoreline retreat: time to abandon the Bruun Rule. Global and Planetary Change, 43(3-4): 157-171.

Corrêa I.C.S. 1996. Les variations du niveau de la mer durant les derniers 17.500 ans BP. l'exemple de la plateforme continentale du Rio Grande do Sul-Brésil. Marine Geology, 130(12): 163-178

Cowell, P.J., Roy, P.S. \& Jones, R.A. 1995. Simulation of LSCB using a Morphological Behaviour Model. Marine Geology, 126: 45-61. Cowell, P.J., Stive, M.J.F., Niedoroda, A.W., Swift, D.J.F., De Vriend, H.J., Buijsman, M.C., Nicholls, R.J., Roy, P.S., Kaminsky, G.M., Cleveringa, J., Reed, C.W. \& De Boer, P.L. 2003b. The coastal-tract (part 2): A conceptual approach to aggregated coastal modeling of low-order coastal change. Journal of Coastal Research, 19: 828-848.

Cowell, P.J., Stive, M.J.F., Niedoroda, A.W., Vriend, H.J., Swift, D.J.P., Kaminsky, G.M. \&
Capobianco, M. 2003a. The coastal-tract (part 1): A conceptual approach to aggregated coastal modeling of low-order coastal change. Journal of Coastal Research, 19: 812-827.

Cowell, P.J., Thom, B.G., Jones, R.A., Everts, C.H. \& Simanovic, D. 2006. Management of uncertainty in predicting climate-change impacts on beaches. Journal of Coastal Research, 22: 232-245.

Daley, M. 2005. Effects of rock truncation on shoreface profile geometry. Sydney, 16p. Bachelor of Science, Environment and Heritage Department, Geocoastal Research Group, University of Sydney.

Da Silva, L.M., De Freitas, S.R.C. \& Dalazoana, R. 2016. Análise de séries temporais maregráficas correlacionadas com observações GNSS no datum vertical brasileiro de Imbituba-SC. Revista Brasileira de Cartografia, 68(1): 73-90.

Davies, J.L. 1980. Geographical Variation in Coastal Development. Nova York, Longman, $224 p$.

Dillenburg, S.R. \& Barboza, E.G. 2014. The strikefed sandy coast of Southern Brazil. In: Martini IP, Wanless HR (eds) Sedimentary Coastal Zones from High to Low Latitudes: Similarities and Differences. Geological Society, 388: 333352.

Dillenburg, S.R., Esteves, L.S. \& Tomazelli, L.J. 2004. A critical evaluation of coastal erosion in Rio Grande do Sul, Southern Brazil. Anais da Academia Brasileira de Ciências, 76: 611-623. Dillenburg, S.R., Roy, P.S., Cowell, P.J. \& Tomazelli, L.J. 2000. Influence of Antecedent Topography on Coastal Evolution as Tested by the Shoreface Translation Barrier model (STM). Journal of Coastal Research, 16: 71-81.

Dillenburg, S.R., Tomazelli, L. J. \& Clerot, L.C.P. 2003. Gradients of wave energy as the main factor controlling the evolution of the coast of Rio Grande do Sul in southern Brazil during the Late Holocene. In: PROCEEDING OF COASTAL SEDIMENTS, 2003, Clearwater Beach.

Dillenburg, S.R., Tomazelli, L.J. \& Barboza, E.G. 2004. Barrier evolution and placer formation at Bujuru southern Brazil. Marine Geology, 203: 43-56.

Dillenburg, S.R., Tomazelli, L.J., Martins, L. R. \& Barbosa, E. G. 2005. Modificações de longo e 
curto período da linha de costa das barreiras do Rio Grande do Sul. GRAVEL, 3: 9-14.

Figueiredo, S.A. 2011. External forcing and internal controls on coastal response to climate change at Rio Grande do Sul, southern Brazil. Sydney, 164p. Doctoral Thesis, Doctor of Philosophy in Science, University of Sydney.

Figueiredo, S.A. 2013. Modeling climate change effects in southern Brazil. Journal of Coastal Research, 65(SI): 1933-1938.

Figueiredo, S.A., Calliari, L.J. \& Machado, A.A. 2018. Modelling the effects of sea-level rise and sediment budget in coastal retreat at Hermenegildo beach, Southern Brazil. Brazilian Journal of Oceanography, 66: 210-219.

Fletcher, C.H. 1992. Sea-level trends and physical consequences - applications to the United States shore. Earth Science, 33(2): 73-109.

Ford, M. 2013. Shoreline changes interpreted from multi-temporal aerial photographs and high-resolution satellite images: Wotje Atoll, Marshall Islands. Remote Sensing of Environment, 135: 130-140.

Gornitz, V. 1991. Global coastal hazards from future sea-level rise. Global and Planetary Change, 89(4): 379-398.

Goulart, E.S. 2010. Morfodinâmica da antepraia adjacente ao Farol da Conceição: litoral médio do RS. Rio Grande, 89p. Dissertação de Mestrado, Programa de Pós-graduação em Oceanografia, Instituto de Oceanografia, Universidade Federal do Rio Grande.

Gutierrez, B.T., Plant, N.G. \& Thieler, E.R. 2011. A Bayesian network to predict coastal vulnerability to sea level rise. Journal of Geophysical Research: Earth Surface, 116(2): 1-15.

Hallermeier, R.J. 1980. A profile zonation for seasonal sand beaches from wave climate. Coastal Engineer, 4: 253-277.

Hands, E.B. 1983. The Great lakes as a test model for profile response to sea level changes. In: Komar, P.D. (Ed.). Handbook of coastal processes and erosion. CRC Press, Boca Raton, Florida, p. 176-89.

IPCC. Intergovernmental Panel on Climate Change. 2014. Climate Change 2014: Synthesis Report. Contribution of Working Groups I, II and III to the Fifth Assessment Report of the
Intergovernmental Panel on Climate Change [Core Writing Team, R.K. Pachauri and L.A. Meyer (eds.)]. Geneva, Switzerland, IPCC, $151 \mathrm{p}$.

Jackson, L.P. \& Jevrejeva, S. 2016. A probabilistic approach to 21 st century regional sealevel projections using RCP and High-end scenarios. Global and Planetary Change, 146: 179-189.

Le Cozannet, G., Garcin, M., Petitjean, L., Cazenave, A., Becker, M., Meyssignac, B., Walker, P., Devilliers, C., Le Brun, O., Lecacheux, S., Baills, A., Bulteau, T. Yates, M. \& Wöppelmann, G. 2013. Exploring the relation between sea level rise and shoreline erosion using sea level reconstructions: an example in French Polynesia. Journal of Coastal Research, 65(SI): 2137-2142.

Le Cozannet, G.L., Garcin, M., Yates, M., Idier, D. \& Meyssignac, B. 2014. Approaches to evaluate the recent impacts of sea-level rise on shoreline changes. Earth Science Reviews, 138: 47-60.

Lima, S.F., Almeida, L.E.S.B. \& Toldo Jr., E.E. 2001. Estimate of alongshore sediment transport from wave data at Rio Grande do Sul coast. Pesquisas, 28: 99-107.

List, J.H., Sallenger, A.H., Hansen, M.E. \& Jaffe, B.E. 1997. Accelerated relative sea-level rise and rapid coastal erosion: testing a causal relationship for the Louisiana barrier islands. Marine Geology, 140(3-4): 347-365.

Long, N., Millescamps, B., Guillot, B., Pouget, F. \& Bertin, X. 2016. Monitoring the topography of a Dynamic tidal inlet using UAV imagery. Remote Sensing, 8(5): 387.

Machado, A. 2014. Estudo dos padrões atmosféricos sinópticos geradores de eventos extremos de altura de onda, intensidade de vento, marés meteorológicas e erosão na costa do Rio Grande do Sul. Rio Grande, 87p. Tese de Doutorado, Programa de Pós-graduação em Oceanografia, Instituto de Oceanografia Universidade Federal de Rio Grande.

Mancini, F., Dubbini, M., Gattelli, M., Stecchi, F., Fabbri, S. \& Gabbianelli, G. 2013. Using Unmanned Aerial Vehicles (UAV) for HighResolution Reconstruction of Topography: The Structure from Motion Approach on Coastal 
Environments. Remote Sensing, 5: 6880-6898.

Martinho, C.T., Dillenburg, S.R. \& Hesp, P. 2009.

Wave Energy and Longshore Sediment

Transport Gradients Controlling Barrier

Evolution in Rio Grande do Sul, Brazil. Journal of Coastal Research, 252: 285-293.

Milne, G.A., Gehrels, W.R., Hughes, C.W. \&

Tamisiea, M.E. 2009. Identifying the causes of sea-level change. Nature Geoscience, 2: 471478.

Motta, L.M.D., Toldo, Jr., E.E., De Sá, L.E., De Almeida, B. \& Nunes, J.C. 2015. Sandy sediment budget of the midcoast of Rio Grande do Sul, Brazil. Journal of Marine Research, 73(3-4): 49-69.

Nicholls, R., Hinkel, J., Tol, R., Boot, G., Vafeidis, A. \& McFadden, L. 2011. A global analysis of coastal erosion of beaches due to sea-level rise: an application of DIVA. In: THE PROCEEDING OF COASTAL SEDIMENTS, 2011, Miami, Florida. World Scientific, Singapore, p. 313-326.

Nicholls, R.J. \& Stive, M.J.F. 2004. Society and sea-level rise requires modelling. Science Magazine, E-Letters, 303: 5665.

Pereira, P.S., Calliari, L.J., Barletta, R.C., Antiqueira, J.A. \& Guedes, R.C. 2007. Variação Decadal dos Perfis Praiais do Farol da Conceição e terminal Turístico, Rio Grande do Sul, Brasil. In: XII COLACMAR, 2007, Florianópolis -SC.

Pilkey, O.H., Young, R.S., Riggs, S.R., Smith, A.W.S., Wu, H. \& Pilkey, W.D. 1993. The concept of shoreface profile of equilibrium: a critical review. Journal of Coastal Research, 9(1): 255278.

Rosa, M.L.C.C., Barboza, E.G., Abreu, V.S., Tomazelli, L.J. \& Dillenburg, S.R. 2017. Highfrequency sequences in the Quaternary of Pelotas Basin (coastal plain): a record of degradational stacking as a function of longerterm base-level fall. Brazil Journal of Geology, 47(2):183-207.

Romine, B.M., Fletcher, C.H., Barbee, M.M., Anderson, T.R. \& Frazer, L.N. 2013. Are beach erosion rates and sea-level rise related in Hawaii? Global and Planetary Change, 108: 149-157.

Romeu, M.A.R., Fontoura, J.A.S. \& Melo, E. 2015. Typical scenarios of wave regimes off Rio Grande do Sul, Southern Brazil. Journal of
Coastal Research, 31(1): 61-68.

Roy, P., Cowell, P.J., Ferland, M.A. \& Thorn, B.G. 1995. Wave dominated coasts. In: Carter, R.W.G., Woodroffe, C.D. (Eds.). Coastal Evolution. Cambridge University Press, p. 121186.

Sallenger, A.H., Doran, K. S.Jr. \& Howd P.A. 2012. Hotspot of accelerated sea-level rise on the Atlantic coast of North America. Nature Climate Change, 2(12): 884-888.

Scarelli, F.M., Cantelli, L., Barboza, E.G., Rosa, M.L.C.C. \& Gabbianelli, G. 2016. Natural and Anthropogenic coastal system comparison using DSM from a low-cost UAV survey (Capão Novo, RS/Brazil). Journal of Coastal Research, 75(SI): 1232-1236.

Scarelli, F.M., Sistilli, F., Fabbri, S., Cantelli, L., Barboza, E.G. \& Gabbianelli, G. 2017. Seasonal dune and beach monitoring using photogrammetry from uav surveys to apply in the ICZM on the Ravenna coast (EmiliaRomagna, Italy). Remote Sensing Applications: Society and Environment, 7: 27-39.

Shearman, P., Bryan, J. \& Walsh, J.P. 2013. Trends in Deltaic Change over Three Decades in the Asia-Pacific Region. Journal of Coastal Research, 29 (5): 1169-1183.

Slott, J.M., Murray, A.B. \& Ashton, A.D. 2010. Large-scale responses of complex-shaped coastlines to local shoreline stabilization and climate change. Journal of Geophysical Research: Earth Surface, 115(F3): 1-19.

Speranski, N. \& Calliari, L. J. 2000. Bathymetric lenses and localized coastal erosion. Journal of Coastal Research, 34(SI): 209-215.

Stive, M.J.F. 2004. How important is global warming for coastal erosion? Climate Change, 64: 27-39.

Tomazelli, L.J. \& Dillenburg S.R. 1998. O uso do registro geológico e geomorfológico na avaliação da erosão de longo prazo na costa do Rio Grande do Sul. Geosul 14: 47- 53.

Tomazelli, L.J., Dillenburg, S.R. \& Villwock, J.A. 2000. Late Quaternary Geological History of Rio Grande do Sul Coastal Plain, Southern Brazil. Revista Brasileira de Geociências, 30: 474-476.

Tomazelli, L.J. \& Villwock, J.A. 1992. Considerações sobre a o ambiente praial e 
a deriva litorânea de sedimentos ao longo do litoral norte do Rio Grande do Sul, Brasil. Pesquisas, 19: 3-12.

Tomazelli, L.J., Villwock, J.A., Dillenburg, S.R. \& Dehnhardt, B.A. 1998. Significance of presentday coastal erosion and marine transgression, Rio Grande do Sul, Southern Brazil. Annais da Academia Brasileira de Ciencias, 70: 221-229.

Villwock, J.A. \& Tomazelli, L.J. 1995. Geologia costeira do Rio Grande do Sul. Notas Técnicas, 8: 1-45.

Villwock, J.A., Tomazelli, L.J., Loss, E.L., Dehnhardt, E.A., Horn Filho, N.O., Bachi, F.A. \& Dehnhardt, B.A. 1986. Geology of the Rio Grande do Sul Coastal Province. Quaternary of South America and Antarctic Peninsula, 4: 79-97.

Webb, A.P. \& Kench, P.S. 2010. The dynamic response of reef islands to sea-level rise: Evidence from multi-decadal analysis of island change in the Central Pacific. Global Planet Change, 72(3): 234-246.

Zhang, K., Douglas, B. \& Leatherman, S. 2004. Global warming and coastal erosion. Climate Change, 64: 41-58. 